\title{
La tragedia clásica de Bécquer en el «Libro de cuentas»
}

\author{
The classical tragedy of Bécquer's \\ «Account book»
}

\author{
Carlos Rizos \\ Universitat de Lleida
}

\section{RESUMEN}

Se presenta aquí el estudio y la edición crítica «definitiva» de la «Tragedia sin título» de Bécquer a partir de la identificación de su fuente, el libreto de Pietro Metastasio titulado Demofoonte. Se distingue de la «tragedia clásica» que dice haber escrito Bécquer en su adolescencia y se relaciona con la «tragedia griega clásica en italiano» titulada La hija del poeta que figura entre sus «Pensamientos de obras originales». Se hace también un bosquejo de los referentes clásicos en los poemas que Bécquer escribió en el «Libro de cuentas» que heredó de su padre, que es donde escribió su Demofoontes.

Palabras Clave: Bécquer, Metastasio, ópera, tragedia, neoclasicismo.

\begin{abstract}
This article consists of an analysis and a «definitive» critical edition of the Becquer's «Tragedy without title» because we have found his source, the Pietro Metastasio's libretto Demofoonte. We distinguish this work from the «classical tragedy» that Becquer names when he talks about his adolescence, and we connect Demofoonte with the «greek tragedy classical in Italian» The Poet's daughter, work that Becquer includes between his «Thoughts of original works». We sketch also classical references that we find in the poems that Becquer wrote in his father's «Account book», where he wrote also her Demofoontes.
\end{abstract}

Key words: Bécquer, Metastasio, Opera, Tragedy, Neoclassicism.

En un comunicado que Gustavo Adolfo Bécquer dirigió al periodista Juan de la Rosa González (quien había sometido a una dura crítica su zarzuela $L a$ cruz del valle) en el periódico La Iberia (11-XI-1860), le hace un «ligerísimo bosquejo de mi corta vida literaria» (contaba entonces veinticuatro años y había de vivir diez más):

Yo no sé si por buena o mala ventura me dediqué muy joven a las letras, pero sí que lo hice por necesidad. Comencé por donde comienzan casi todos: por escri- 
bir una tragedia clásica y algunas poesías líricas. Esto es lo que en lenguaje técnico llamamos pagar la patente de inocencia. La primera la guardo; de las segundas se publicaron varias (Bécquer, 2004: 1634-1635)

Vemos que Bécquer alude a su primera etapa de escritor con cierta sorna: «pagar la patente de inocencia». No muy distinto es el tono con que se refiere a esa etapa de su vida literaria en la tercera de las cartas Desde mi celda (El Contemporáneo, 5-VI-1864):

Cuando yo tenía catorce o quince años y mi alma estaba henchido de deseos sin nombre, de pensamientos puros y de esa esperanza sin límite, que es la más preciada joya de la juventud; cuando yo me juzgaba poeta, cuando mi imaginación estaba llena de esas risueñas fábulas del mundo clásico, y Rioja en sus silvas a las flores, Herrera en sus tiernas elegías, y todos mis cantores sevillanos, dioses penates de mi especial literatura, me hablaban de continuo del Betis majestuoso, el río de las ninfas, de las náyades y los poetas, que corre al océano, escapándose de un ánfora de cristal, coronado de espadañas y laureles (Bécquer, 2004: 402)

Años más tarde, Narciso Campillo —íntimo amigo de Bécquer en esta su primera etapa- recordará en su necrológica:

Me complazco en recordar esta época de nuestro primer vagido literario; y digo nuestro porque, siendo él de diez años y yo de once, compusimos y representamos en dicho colegio [el de San Telmo, en Sevilla] un espantable y disparatado drama que se titulaba, si mal no recuerdo, Los conjurados (Narciso Campillo, La Ilustración de Madrid, 15-I-1871).

No sabemos qué habrá ocurrido con el drama Los conjurados (escrito al alimón entre Bécquer y Campillo en la infancia de sus diez u once años), aunque, por los calificativos que le aplica Campillo (espantable y disparatado), seguramente no ha sido una gran pérdida. Lo que sí es muy probable es que la «tragedia clásica» que dice conservar Bécquer a finales de 1860 esté relacionada con las «risueñas fábulas del mundo clásico» sobre las que escribió en su adolescencia (catorce o quince años) según nos cuenta en Desde mi celda. Lo que ya no podemos asegurar es que esa tragedia clásica se pueda identificar con los retazos dramáticos escritos en endecasílabos que nos han llegado de puño y letra de Bécquer en el que fuera «Libro de cuentas» de su padre (manuscrito conservado en la Biblioteca Nacional de Madrid con el número 22.511).

Los textos de Gustavo Adolfo que incluye el manuscrito se debieron de escribir entre el otoño de 1848 (pues incluye la elegía «A la muerte de Don Alberto Lista», que falleció el 5 de octubre de ese año) y el otoño de 1854 en que partió hacia Madrid para emprender una nueva etapa literaria. Aunque algunos de esos textos se han ido publicando desde bien temprano (fundamentalmente poemas líricos ${ }^{1}$, aunque también el diario adoles-

${ }^{1}$ En las últimas ediciones de las Obras completas de la editorial Aguilar se incluyen: «Oda a la muerte de don Alberto Lista» (38r) y, bajo la rúbrica de «Fragmentos», los poe- 
cente $^{2}$ ), la mayor parte del manuscrito no ha visto la luz hasta que en 1993 lo publicó Leonardo Romero Tobar (Bécquer, 1993: 145-163) en una transcripción que va acompañada del facsímil. En esta incluye todo el texto dividido en cuatro apartados: 1) Poemas, 2) Prosas, 3) Hamlet y sus comentarios, 4) Tragedia sin título (fragmentos).

En cuanto a las prosas que escribió Bécquer en el libro de cuentas, merece aquí una especial atención una en que el poeta adolescente traduce en lo que debió de ser un ejercicio de latín, pues la dicha traducción va acompañada de un comentario gramatical:

Como $^{3}$ Aníbal Cartaginense llegase o viniese desterrado o expulsado a ${ }^{4}$ Antíoco rey de Éfeso, fue invitado o convidado por el que lo hospedaba para oír a Formión, filósofo peripatéticos. ${ }^{5}$ Diciéndole:.... $)^{6}$.

\section{Y el comentario gramatical:}

El recíproco primitivo suis $^{7}$ se refiere precisamente al sujeto del verbo cuando es tercera persona y se pone el caso que pida el verbo. Igualmente el posesivo mii no puede concertar sino con un nombre que expresa cosa poseída por el sujeto del verbo. Cualquiera nombre, verbo, adjetivo y participio puede construirse con dativo de adquisición.

Todo acusativo que no fuera el término de la acción del verbo, sujeto o predicado del infinitivo, es regido de una preposición clara inoculta ${ }^{8}$ y todo ablativo igualmente.

El verbo compuesto de preposición puede regir el caso que esta pide tácita o expresa(mente).

Suele juntarse el verbo.

mas que empiezan «Cuántas veces también en la colina» (veremos que en realidad es un fragmento de la tragedia que aquí nos va a ocupar: $31 \mathrm{v}$ ), «¿Quién es la ninfa de inmortal belleza...» (34r y 46r), «La luna entre las nubes se escondía» (66r), así como la «Anacreóntica» (42r; ya publicado por Bécquer en el Álbum de Señoritas y Correo de la Moda, 16IX-1855).

${ }^{2}$ Publicado por Dámaso Alonso (1961).

${ }^{3}$ Debajo, tachado: [cuando].

${ }^{4}$ Sigue, tachado: [Éfeso].

${ }^{5}$ Romero Tobar (R.T.) transcribe «viese» en lugar de «viniese» $\mathrm{y}$ «Fornios» en vez de «Formión».

${ }^{6}$ El joven Bécquer aquí está traduciendo el siguiente pasaje de Cicerón (De oratore, XVIII, 75): Nec mihi opus est Graeco aliquo doctore, qui mihi pervolgata praecepta decantet, cum ipse nunquam forum, nunquam ullum iudicium aspexerit; ut Peripateticus ille dicitur Phormio, cum Hannibal Carthagine expulsus Ephesum ad Antiochum venisset exul proque eo, quod eius nomen erat magna apud omnis gloria, invitatus esset ab hospitibus suis, ut eum quem dixi, si vellet, audiret. (resalto en negrita el pasaje que traduce y en redonda las palabras que son objeto de comentario). La no aparición de la proposición de relativo «quod eius nomen erat magna apud omnis gloria» seguramente se debe a que Bécquer no parte del texto de Cicerón directamente sino de algún ejercicio escolar que lo habría adaptado.

${ }^{7}$ R.T. y Navas Ruiz (N.R.) transcriben «sui»

${ }^{8}$ R.T. y N.R. dejan como ilegible esta palabra. 
Pero centrémonos ya en la «Tragedia sin título», nombre que le da Romero Tobar en su edición del libro de cuentas, y que él mismo relacionó con la «tragedia clásica» a que aludía Bécquer rememorando su adolescencia (Bécquer, 1993: 24). Sebold (1999: 79) ha apuntado que también podría estar relacionada con uno de los «Pensamientos de obras originales» que dejó antes de morir, «La hija del Poeta: tragedia: griega: clásica: Italiano)»9 .

El único fragmento que se había publicado de los fragmentos de la «tragedia clásica» que aparecen en el libro de cuentas es aquel que empieza «Cuántas veces también en la colina» (incluido ya en las últimas ediciones de las Obras Completas en la editorial Aguilar ${ }^{10}$ ), que aparece en los folios $31 \mathrm{v}$ y 32r. Romero Tobar fue el primero en editar los fragmentos de la tragedia y se ocupó de reivindicar ese que se ha tomado por «poema» como parte de la tragedia (Bécquer, 1993: 25). Los criterios que sigue para considerar los distintos pasajes como parte de la pieza son los siguientes: 1) versificación en endecasílabos, 2) los nombres de los personajes aludidos, 3) estilo grandilocuente (Bécquer, 1993: 31). Dado que no logra reconstruir el hilo general de la trama, presenta los fragmentos por orden de aparición en el libro de cuentas, aunque distinguiendo entre «fragmentos breves» ${ }^{11} \mathrm{y}$ «fragmentos extensos» ${ }^{12}$. Dado que en el manuscrito no aparecen los nombres de los personajes que hablan en cada momento, el editor propone quién puede hablar en cada caso. Además, como en el original no se deja ningún espacio entre los versos para separar los distintos parlamentos, es difícil saber dónde empieza o termina de hablar cada personaje, lo que se complica aun más cuando en un mismo verso habla más de un personaje. También en esto ha arriesgado el editor una separación de los parlamentos para atribuir cada uno al personaje correspondiente. Ofrece asimismo, como edición crítica que es, las segundas versiones y retractationes en notas a pie de página. Descontento con no po-

\footnotetext{
${ }^{9}$ Se cita tradicionalmente como «tragedia griega, clásico-italiana» (así en Bécquer, 2004, p. 1625) siguiendo la edición del texto por Alberto de Segovia (1927: 25), que es la que sigue Gamallo de Fierros (1948: 431-437), a quien siguen todos los demás, pero en la primera edición del texto en el artículo anónimo «Páginas inéditas de Bécquer» (Anónimo, 1920: 10) se transcribe «Tragedia griega, clásica-Italiano», que sigue lo que leemos en el manuscrito, que he localizado en la Fundación Vicente Huidobro (Santiago de Chile) con el número MS-171. Agradezco a la coordinadora de la fundación, la Sra. Liliana Rosa, el haberme facilitado copia escaneada del manuscrito.

${ }^{10}$ Este pasaje fue dado a conocer por Luis de Armiñán (1939), citado por Pageard (1990: 66-70).

${ }^{11}$ Son los siguientes: el que menciona a Yocasta (31r); un pasaje suelto en que se menciona a Querinto (39v); un fragmento en que se menciona a Geruta (76v), madre de Hamlet, acaso - propone- por confusión con Creúsa, que interviene, como Querinto, en los fragmentos extensos, y otro fragmento de cuatro versos en que se alude a alguien que entra en la morada de sus padres con un arma blanca (96v).

${ }^{12}$ Separados en seis bloques en función — suponemos- de los personajes que aparecen: frag. A (3v, Dircea y Padre), frag. B. (4v y 7v, Querinto y Creúsa), frag. C (8v y 9v, Dircea y Timantes), frag. D (31v y 32r, Timantes y Dircea), frag. E (43v, 44r, 45v, 46r y 46v, Timantes, Dircea y Padre) y frag. F (147r, 147v y 148r, Querinto y Creúsa).
} 
dernos brindar una edición mejor, Romero Tobar invita a seguir indagando con el famoso verso de Ariosto: Forse altri canterà con miglior plettro.

Dos años más tarde aparecieron unas Obras completas de Bécquer en la editorial Turner de la mano de Ricardo Navas Ruiz (Bécquer, 1995: I, 155 176). En esta edición se mantiene el calificativo de «Tragedia sin título: fragmentos». En ella, que no es una edición crítica (no tiene notas ni da la paginación del manuscrito), arriesga una ordenación de los fragmentos dándole al texto cierta coherencia, aunque no termina de cuadrar del todo. Se abstiene de proponer el nombre de los personajes que hablan en cada momento, aunque sí separa sus parlamentos. También da una separación de los fragmentos por medio de asteriscos, seguramente atendiendo a posibles cambios de escena o simplemente a lagunas del hilo argumental. Asimismo ofrece una sección de «Fragmentos inconexos» donde incluye el de Yocasta (31r), dos estrofas de cuatro y cinco versos respectivamente (32r; Romero Tobar los incluyó entre los poemas no relacionados con la tragedia ${ }^{13}$ ) y seis versos que son, a todas luces, un inicio alternativo del fragmento que empieza en el folio $43 \mathrm{v}$ (frag. E de la edición de Romero Tobar), en cuya parte superior, de hecho, se encuentran esos versos, separados por una raya horizontal. En cambio, dos de los fragmentos que Romero Tobar consideró como vinculados a la tragedia (el que menciona a Geruta [76v] y el que presenta a un personaje que entra en la morada de sus padres con un arma blanca en las manos [96v]), son incluidos por Navas Ruiz entre los fragmentos sueltos del Hamlet.

En el año 2004 aparecieron unas Obras completas de Bécquer en la editorial Cátedra a cargo de Joan Estruch Tobella. Este editor excluye la «tragedia sin título» porque, según apunta en la introducción, «resulta imposible realizar una lectura coherente de la misma» (Bécquer, 2004: 36). Aquí vamos a ocuparnos de demostrar lo contrario. En el mismo lugar dice que «está basada en la tragedia clásica Edipo». La única tragedia titulada Edipo que nos ha legado la antigüedad es la que escribió Séneca. Seguramente se refiere al Edipo Rey de Sófocles, que puede ser (más que el Edipo en Colono) un punto de referencia para el fragmento que hemos llamado de Yocasta (31r), pues aparece esta preguntando por Edipo a un personaje (que podría ser su marido Layo) que le dice que Edipo está lejos y oculto y que no es seguro verlo (por no decirle que lo ha mandado matar); el secreto al que alude quizá podría relacionarse con la revelación del oráculo, que le vaticinó que el hijo que tuviera lo iba a matar, razón por la que lo manda matar al nacer. No obstante, en el Edipo Rey el protagonista ya aparece como rey de Tebas, aunque sí se revela allí, cuando averigua que mató a su padre y que se ha casado con su madre, lo que había sucedido antes.

${ }^{13}$ Comparto la posición de Romero Tobar, pues, aunque están compuestos en endecasílabos, no veo modo de conectarlos con el resto de la tragedia, y su contenido es más lírico que otra cosa. 


\section{PROBLEMAS ECDÓTICOS Y FUENTES}

Los principales problemas que encontramos para la edición de los fragmentos de la «tragedia clásica» del libro de cuentas son los siguientes:

- Los fragmentos están esparcidos por diferentes hojas del libro sin ningún criterio ${ }^{14}$.

- Dentro de una misma hoja los fragmentos no siempre van seguidos, sino que depende del espacio de que disponga en función de lo que ya había escrito y del lugar por donde decidió empezar a escribir en cada hoja ${ }^{15}$.

- Los parlamentos de los personajes no están separados (ni siquiera cuando hay varios en un mismo verso).

- Los parlamentos no van encabezados por el nombre del personaje que los pronuncia.

- La alternancia de nombres propios ligados a la tragedia clásica (Yocasta, Edipo, Creúsa, Demofoontes, Adrasto, Dircea ${ }^{16}$, Olinto) con otros que reconocemos como personajes históricos (Timantes y Querinto ${ }^{17}$ ).

- La aparición de poemas (o textos de otro tipo) no relacionados con la tragedia en hojas donde tenemos fragmentos de la misma ${ }^{18}$.

${ }^{14}$ Concretamente: $3 \mathrm{v}, 4 \mathrm{v}, 7 \mathrm{v}, 8 \mathrm{v}, 9 \mathrm{v}, 20 \mathrm{r}, 31 \mathrm{r}, 31 \mathrm{v}, 32 \mathrm{r}, 39 \mathrm{v}, 43 \mathrm{v}, 44 \mathrm{r}, 45 \mathrm{v}, 46 \mathrm{r}, 46 \mathrm{v}$, $147 \mathrm{r}, 147 \mathrm{v}$ y $148 \mathrm{r}$.

${ }^{15}$ El ejemplo más claro está en los folios 31v y 32r: en 32r estaban los dos poemitas de cuatro y cinco versos respectivamente que he reproducido en la nota 34; sobre ellos había un rótulo del padre del poeta que dice «1841 / Cuentas y Apuntes pertenecientes a este año»; este fragmento de la tragedia empieza en la parte inferior derecha (después de los poemitas; vv. 45-54 de la edición de R.T.); continúa en la parte inferior izquierda (vv. 7-20 de R.T.); sigue en la parte superior derecha (vv. 21-32 de R.T.); después, al topar con el rótulo, pasa a la parte superior izquierda (vv. 1-6 de R.T.); al encontrarse de nuevo con el rótulo (ahora antes porque estaba el año), sigue en la parte central izquierda (bajo el rótulo y en paralelo a los dos poemitas; vv. 33-44 de R.T.); pasa entonces a la página anterior (31v), debajo de unas cuentas del padre, en la zona derecha (vv. 17-36 de R.T.); al llegar al final de la hoja, pasa a la zona izquierda (vv. 1-16 de R.T.); la continuación de este fragmento está en la página anterior (31r), con el fragmento de Yocasta, aparentemente no relacionado. Menos problemáticos son otros casos. En el fol. 4v, cuando se le termina la hoja, sigue en el margen, escribiendo en vertical. En el 46r escribe sobre la hoja donde tenía la segunda versión de «¿Quién es la ninfa de inmortal belleza...», escrito en dos columnas, siendo la derecha más corta que la izquierda: empieza a escribir bajo la derecha, tras una raya que marca el final del poema, y cuando llega al final de la hoja, sigue bajo la columna izquierda del mencionado poema. Después continúa en la página anterior $(45 \mathrm{v})$, en la parte inferior, tras una raya horizontal que lo separa de otro pasaje anterior de la tragedia.

${ }^{16}$ Dircea podría ser variante de Dirce, que aparece en el Heracles de Eurípides. Todos los demás son también personajes de tragedias de Eurípides, salvo Yocasta y Edipo que son del Edipo Rey de Sófocles.

${ }^{17}$ Timantes fue un célebre pintor griego y Cerinto es el nombre de un hereje del cristianismo más temprano, además del nombre de una ciudad de Eubea.

${ }^{18}$ En el folio 31v leemos en medio de los versos de la tragedia, aunque con caligrafía diferente del mismo Gustavo Adolfo: «Cuando del Betis» (asociable al poeta que canta al 
- La aparición de una acotación que encabeza el folio $147 \mathrm{r}$ donde leemos: «Aquiles / acto $1^{\circ}$. Tumba de Héctor: Príamo, Eneas, Edipo, Paris, siervos, nobles y pueblo. Se hace / la esposición / y de estupor me llena / Aquiles / acto $1^{\circ} /$ Acto $1^{\circ} »$. La frase «y de estupor me llena» coincide con el v. 6 de la misma página, por lo que debe extraerse de la acotación ${ }^{19}$.

- Problemas estrictamente paleográficos no hay apenas. La letra es clara aunque a veces hay manchas de tinta. Son frecuentes las retractationes, que dan lugar a tachaduras, segundas versiones (de versos o de estrofas o de simples palabras), etc.

Frente a todos estos problemas que llevaron a Estruch Tobella a afirmar que es imposible hacer una lectura coherente, ha sido preciso buscar las relaciones de sentido entre los distintos fragmentos para reconstruir un texto algo más coherente. Esta es la labor que llevó a cabo Navas Ruiz al realizar su edición reordenando los fragmentos que Romero Tobar presentó en estricto orden de aparición. Pero la clave para obtener una lectura totalmente coherente está en tener en cuenta que la que hasta ahora se ha venido llamando «tragedia sin título» no es otra cosa que una versión —en parte traducción y en parte adaptación - del primer acto de la ópera de Pietro Metastasio titulada Demofoonte $(1733)^{20}$. Exactamente corresponde a los versos que van del 51 al 445 de la pieza de Metastasio; desde el principio de la segunda escena hasta la mitad de la undécima ${ }^{21}$, del total de trece escenas (504 versos) de que consta ese primer acto (de los tres que forman el libreto de Metastasio). En efecto, esta es la piedra de Rosetta que necesitábamos para reconstruir la tragedia que Bécquer nos dejó en el libro de cuentas de su padre. Mediante el

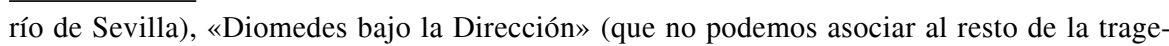
dia por más que el nombre sea mitológico). En el folio 32r incluye los dos poemitas de cuatro y cinco versos que Navas Ruiz consideró relacionados con la tragedia y que he transcrito en la nota 58. En el folio 46r incluye también la segunda versión del poema «iQuién es la ninfa de inmortal belleza...?», aunque está claramente separado. En el folio 147r incluye, al principio, seis versos escritos con una caligrafía distinta del propio Gustavo Adolfo; su tono es lírico (empieza «No bala triste el simple corderillo...») y también pertenecen al Bécquer cantor de su Sevilla natal (el último verso también alude a la orilla del Betis).

${ }^{19}$ Seguramente la escribió allí mientras elaboraba este pasaje de la tragedia sin título. Escribe «Edipo» encima de «Eneas». Esta acotación puede estar relacionada con la anotación del folio 31v que rezaba «Diomedes bajo la Dirección». Se trataría entonces de una tragedia de tema troyano, aunque Edipo es cronológicamente anterior a la guerra de Troya.

${ }^{20}$ Esta obra de Metastasio ya había sido traducida al castellano mucho antes de Bécquer, y repetidamente editada. Fue traducida por primera vez por José Poma como El Demofoonte (Madrid, 1738). Ediciones posteriores fueron las siguientes: 1751 (una edición en Madrid y otra en Barcelona), 1755 (Madrid), 1764 (Cádiz), 1767 (Palma), 1791 (Madrid; traducida por Ignacio García Malo con el título de El inocente usurpador). Todas las ediciones son bilingües. También hay una adaptación de Ramiro Díaz Sirigo publicada sin año en Sevilla con el título Comedia nueva: El Demofonte.

${ }^{21}$ Hay dos lagunas: vv. 332'-342' (inicio de la sexta escena) y vv. 359-399 (escenas séptima y octava). 
cotejo de la obra de Bécquer con su modelo, no resulta difícil ordenar los fragmentos, separar los parlamentos de cada personaje y atribuir a cada uno el parlamento que le corresponde.

Las correspondencias entre los fragmentos de Bécquer (según la foliación del manuscrito) y la ópera de Metastasio son las siguientes: 32r-31v: vv. 5180; 31r: vv. 81-90; 44r: vv. 150'-181'22; 43v: vv. 181'-195'; 46v: vv. 195'212'; 45v (excepto los últimos 4 vv.): vv. 212'-229; 46r (y últimos 4 vv. del fol. 45v): vv. 230-245; 39v: vv. 246-257'; 4v: vv. 263-281'; 7v: vv. 281'-299; 147r: vv. 300-310; 147v: vv. 314-331; 148r: vv. 342-358; 3v: vv. 400-415; 8v: vv. 416-430'; 9v: vv. 430'-445.

Dado que se trata de una versión más que de una traducción, se sirve a menudo de la amplificatio (y ocasionalmente también de la reductio). Esto da lugar a que los 395 versos de Metastasio se eleven a 470 en la adaptación de Bécquer, teniendo además en cuenta que se salta dos escenas (la séptima y la octava) y el principio de otra (la sexta).

Con todo, quedan pendientes de explicación algunos de los problemas señalados arriba. En la obra de Metastasio aparecen los siguientes personajes ${ }^{23}$ : Demofoontes ${ }^{24}$ (Demofoonte): rey de Tracia; Dircea (Dircea): esposa secreta de Timantes; Creúsa ${ }^{25}$ (Creusa): princesa de Frigia, destinada a ser la esposa de Timantes; Timantes (Timante): supuesto príncipe heredero, hijo de Demofoontes; Cherinto ${ }^{26}$ (Cherinto): hijo de Demofoontes, amante de Creúsa; Matusio ${ }^{27}$ (Matusio): supuesto padre de Dircea y noble de Tracia; Adrasto (Adrasto): capitán de la guardia real y confidente del rey; Olinto (Olinto): hijo secreto de Dircea y Timantes.

\footnotetext{
${ }^{22}$ Con esta virgulilla indico versos incompletos, es decir, una parte del verso. Esto es importante sobre todo cuando en un solo verso interviene más de un personaje.

${ }^{23}$ Doy en primer lugar el nombre en castellano, según la versión de Bécquer, y a continuación, entre paréntesis, el nombre que reciben en italiano.

${ }^{24}$ La forma Demofoontes que emplea Bécquer (que solo aparece una vez: fol. 7v, v. 11) no atiende a la etimología $(\Delta \eta \mu \circ \phi \omega ́ v)$ ni tiene tradición alguna (en italiano Metastasio usa Demofoonte, y la traducción al castellano de José Poma también se titula Demofoonte); tal vez emplea esta forma por analogía con Timantes, que en italiano es Timante. Quizá esto demuestra que Bécquer no conoció la traducción castellana.

${ }^{25}$ Transcribo el nombre con tilde porque es la forma que emplea Bécquer, ya que es la única que permite formar los endecasílabos correspondientes en los lugares donde aparece (fol. $4 \mathrm{v}$, v. 11 ; fol. 7 v, vv. 3 y 23; fol. 147r, v. 4). Además, es la forma correcta etimológicamente, pues parte del griego K $\rho \in$ ṽ $\sigma a$ (y en italiano también se pronuncia con hiato - también en la obra de Metastasio-, a partir del latín Creusa, donde no era diptongo). La forma «Creusa» que ofrecen los editores Romero Tobar y Navas Ruiz no tiene ningún fundamento.

${ }^{26}$ Esta es la forma que emplea Bécquer, siguiendo el modelo italiano (igual que las otras traducciones castellanas), pero en la edición doy, como los editores anteriores, la forma «Querinto», que es la que se ajusta a la ortografía actual manteniendo la pronunciación italiana, aunque la transcripción correcta y etimológica es Cerinto (a partir del griego Kń

${ }^{27}$ Este nombre no aparece en el texto de Bécquer porque no se menciona en ningún parlamento.
} 
En el texto de Bécquer tenemos los mismos nombres, con la excepción del folio 31r (vv. 81-90 de Metastasio), donde encontramos a Yocasta y Edipo, que no aparecen en el modelo italiano. El manuscrito permite ver que los tres primeros versos (que no tienen una correspondencia en la obra de Metastasio) fueron añadidos con posterioridad; están más separados del margen que todos los demás, y la tinta parece diferente. Es en esos versos donde se menciona a Yocasta (empieza con esta palabra). Y lo mismo se puede decir de la palabra Edipo con que termina el primero de los nueve versos restantes (se puede apreciar que ha sido escrita encima con una caligrafía y tinta distintas). Recordemos el pasaje:

Yocasta, no, no llegues a ese lecho,

llegues infeliz, que maldecido

por los Dioses está.

Ah, ¿dónde, dónde está uno que Edipo...? TIMANTE

Llévame, por tu amor, donde se halla.

Modera tu cariño por ahora;

lejos de aquí, y en parte custodiado, oculto vive y el llegar a verlo muy seguro no es. ¡Oh, cuántas ansias cuesta nuestro secreto!

Sí, y me cuesta

DIRCEA
signor per ora il violento affetto. In custodita parte egli vive celato; e andarne a lui non è sempre sicuro. Oh quanta pena costa il nostro segreto!

TIMANTE

ya el fingir el temor a cada instante, como si un crimen nos manchara el alma.
Ah dov' è? Sposa amata, guidami a lui; fa' ch' io lo vegga.

Affrena Ormai son stanco di finger più, di tremar sempre. Io voglio cercar oggi una via d' uscir di tante angustie.

Seguramente este pasaje en que Timantes pregunta a su secreta esposa Dircea por su secreto hijo Olinto recordó a Bécquer el mito de Edipo, hijo de Layo y Yocasta $^{28}$, por lo que habría añadido esa primera estrofa en la que Layo le pide a su esposa que no se acerque a su lecho porque está maldecido por los dioses. Estas palabras deben de ser ominosas, seguramente porque de algún modo prevé lo que el oráculo vaticinó. Las palabras de Timantes preguntando a Dircea por su hijo Olinto le evocaron a Bécquer lo que Yocasta podría haberle preguntado a Layo cuando vio que su hijo recién nacido (que había de llamarse Edipo) no estaba. En efecto, igual que Layo se deshizo de su hijo mandándolo matar y pudo responder a Yocasta que estaba en un lugar oculto y lejano, Dircea le dice a su secreto esposo que su hijo (Olinto) está lejos y oculto, y que es más seguro que no lo vea (porque es el hijo secreto de un matrimonio también secreto). Además, no hay que perder de vista que el incesto es un tema que comparten el Demofoonte y el Edipo Rey, pues en la obra de Metastasio (en la parte que no ha adaptado Bécquer: actos

\footnotetext{
${ }^{28}$ Bécquer escribe en el manuscrito, por encima del pasaje que aquí nos ocupa, cuatro veces la palabra «Yocasta».
} 
II y III) Dircea resulta ser hija de Demofoonte, con lo que pasa a ser hermana de su esposo secreto Timantes, hasta que este descubre que él en realidad es hijo de Matusio. De este modo ya no hay incesto y deja de ser el príncipe heredero, de manera que Querinto se convierte en el nuevo heredero pudiéndose casar con Creúsa, heredera del trono de Frigia, a quien amaba y por quien era correspondido en secreto $^{29}$.

Tal vez podrían observarse otras fuentes que afectarían al estilo que emplea el Bécquer adolescente. Ya otros se han ocupado de señalar los autores que leyó el poeta en esta primera etapa (Pageard, 1990: 52-81), pero todavía nadie había hablado de Metastasio.

\section{CONCLUSIONES}

Queda todavía por resolver la cuestión de si la tragedia que aparece en el libro de cuentas, a la que ya podemos dar el título de Demofoontes, es la «tragedia clásica» que dice haber escrito Bécquer cuando tenía catorce o quince años. Aunque es cierto que los personajes, la época y el lugar de la acción (la antigua Grecia) corresponden a la época clásica, y el contenido de la pieza es propio de una tragedia, Bécquer dice que empezó por «escribir una tragedia clásica». Si aludiera a esta, acaso hubiera dicho «traducir» o «adaptar»; al fin y al cabo nos está hablando de «pagar la patente de inocencia». Considero que la clave está en el apunte (que me he arriesgado en llamar acotación) del folio 147r, donde nos habla de un «acto $1^{\circ}$ » donde aparece la «Tumba de Héctor» con la presencia de «Príamo, Eneas, Edipo, Paris, siervos, nobles, etc...», que son «la espectación»; todo ello bajo el nombre «Aquiles», que podría ser el título.

Ya he avanzado antes que esta acotación podría estar relacionada con el apunte suelto «Diomedes bajo la Dirección» del fol. 31v. Si estuvieran en relación con una tragedia de tema troyano, no resultaría difícil reconstruir «Diomedes, bajo la dirección de Ulises», pues en la Ilíada aparece ese personaje como ayudante del protagonista de la Odisea. Lo que está claro es que ni la acotación ni ese apunte están en relación con el Demofoontes. Son apuntes que quedaron en este libro de cuentas (como tantos otros apuntes, versos, nombres, firmas, etc. que se encuentran), y hacen pensar en una tragedia de tema troyano. En este sentido, lo que demuestra su interés por este tema es sobre todo uno de

\footnotetext{
${ }^{29}$ En cuanto a la fuente de donde puede haber tomado Bécquer el mito de Edipo, no es fácil asegurarlo. Lo cierto es que sí podría haber leído algunas tragedias de Sófocles (este mito está ligado a su Edipo Rey), pues en 1820 las había traducido al castellano Pedro de Montengón. Y precisamente es otra tragedia de Sófocles, la Electra, la que podría estar detrás del fragmento aquel que, partiendo del contenido del Hamlet, escribió pensando en Orestes (fol. 96v): $Y$ con cautela y silenciosa planta / un vengador terrible de los muertos / penetra en la morada de sus padres, / pronto en la mano el homicida acero. Recordemos que también aquí escribe el nombre «Orestes» junto al poema (nada menos que seis veces).
} 
los romancillos del «Libro de cuentas», el que aparece en los folios 57r/56v, donde se menciona a Aquiles (después llamado «hijo de Peleo»), Hécuba, Andrómaca, Áyax, Helena, Mavorte (Marte) y «troyano pueblo». No se puede decir que esos versos formaran parte de la tragedia (lo que apunta Romero Tobar como una posibilidad remota; Bécquer 1993: 25), pues el heptasílabo no es verso para tratar un tema sublime como es la guerra de Troya; recordemos que ese romancillo termina con una recusatio por la que va a empezar a cantar a los pastores — como cantor del Betis, siguiendo el modelo de Alberto Lista- y "el néctar de Lieo» —en lo que fue su anacreóntica.

La tragedia que escribió y que no nos ha llegado seguramente está relacionada con esos escasos apuntes que quedaron en el libro de cuentas. Posiblemente su título fue Aquiles por ser este el nombre que escribió (subrayado) en el centro y en lo alto de la página donde dejó esa acotación con que empezaría el primer acto (y repite Aquiles después de la acotación, en el lado derecho). Así como del Demofoontes no nos ha dejado ninguna acotación (y los nombres de los personajes hemos tenido que indagarlos), del Aquiles - ya digo que este título es muy provisional - no nos ha dejado ni un solo parlamento ( $«$ ¿Diomedes bajo la Dirección» formó parte de uno?).

De hecho, el haber escrito una recusatio donde las musas lo invitan a abandonar «el sublime empleo / de cantar los furores / del hijo de Peleo» puede hacer pensar que realmente escribió algo (¿un poema, una tragedia...?) sobre esta cuestión. Además, ese motivo vuelve a aparecer en un soneto que escribió de adolescente (publicado en la revista El Trono y la Nobleza en diciembre de 1853):

Homero cante a quien su lira Clío le dio, y con ella inspiración divina, de Troya malhadada la ruina, del ciego Aquiles el esfuerzo y brío. Ensalcen de Alejandro el poderío ante cuyo valor su frente inclina con asombro la sierra que ilumina el sol desde la Libia al Norte frío. Que yo del Betis en la orilla, cuando luce la aurora y las gallardas flores se despliegan el aura embalsamando, cantaré de las selvas los amores, los suspiros del céfiro imitando y el dulce lamentar de dos pastores

Aquí se propone escribir poesía bucólica («el dulce lamentar de dos pastores»; Garcilaso de la Vega, Égloga I, v. 1), dejando la épica (Aquiles y Troya) y la historia (Alejandro; Clío es la musa de la historia). ¿Debemos entender este soneto también como una recusatio por la que se arrepiente de lo que más tarde llamaría su «patente de inocencia»? Teniendo en cuenta que este poema es de finales de 1853 (Bécquer tenía entonces diecisiete años), cabe suponer que la «tragedia clásica» sería anterior. Vienen a ser los catorce o quince años en que su «imaginación estaba llena de esas risueñas fábulas del mundo clásico».

En cualquier caso, esa «tragedia clásica» que aún conservaba a finales de 1860 no nos ha llegado. No obstante, sabemos que se salvó de la quema de 
poesías de que da testimonio Narciso Campillo (en su citada necrológica de 1871) en los días que precedieron a su partida a Madrid en el otoño de 1854. Tampoco deben de estar relacionados con una quema de papeles que llevaron a cabo Bécquer y su amigo Augusto Ferrán días antes de la muerte del primero - de lo que da testimonio el escritor de su entorno Florencio Moreno Godino (1886) — , pues al parecer (según contó Ferrán a Moreno Godino) esos papeles podían dañar su honor (Pageard, 1990: 527), y no parece que una «tragedia clásica» escrita en su adolescencia, la «patente de inocencia», pudiera afectar en lo más mínimo al honor del poeta.

En cambio, sí es muy probable que el Demofoontes de Bécquer tenga relación con el drama titulado La hija del poeta (tragedia griega clásica en italiano) que dejó apuntado entre sus «Pensamientos de obras originales» antes de morir, según apuntó Sebold (1999: 79). En efecto, el Demofoontes es una tragedia de tema griego, y es obra original del libretista italiano Pietro Metastasio, un autor neoclásico en toda regla. Además, la obra que menciona a continuación de esta es precisamente el «Hamlet (tragedia del ... moderno)» (Bécquer, 2004: 1625), justamente la obra que comparte espacio con el Demofoontes, ambas incluidas en el libro de cuentas. El único inconveniente es explicar el título, pues aunque podría entenderse que la protagonista del drama podría ser Dircea, esta es hija de Matusio (por más que después se descubre que es hija del rey Demofoonte), un noble de Tracia, pero en ningún lugar consta que fuera poeta. Aquí podría entrar la aportación de Bécquer, quien de hecho también le cambia la condición social cuando Demofoonte dice a Timantes que le pidió liberar a unos esclavos («el perdón que me demandas / a los cautivos doy», fol. 44r, 4-5), lo que no tiene correspondencia alguna con el texto de Metastasio. Menos probable es que la «hija del poeta» sea Creúsa, hija del rey de Frigia, pues su papel es menos importante en la obra.

Por otra parte, con la identificación del modelo que siguió Bécquer en su versión del Demofoonte de Metastasio, queda demostrado que ya desde bien joven demostró Bécquer interés por la música lírica, lo que después iba a dar lugar, no solo a componer cinco zarzuelas (escritas al alimón con Luis García Luna y Ramón Rodríguez Correa), sino también a enamorarse de una cantante de ópera, la soprano Julia Espín, la supuesta inspiradora de sus Rimas. De todas formas, podemos asegurar que Gustavo Adolfo conoció esta obra y este autor únicamente por su lectura, pues no se estrenó ninguna ópera metastasiana en Sevilla desde que empezó a escribir en el «Libro de cuentas» de su padre (1848) hasta que se fue a Madrid en 1854 (Moreno Mengíbar, 1997: 80-89).

\section{ESTA EDICIÓN}

En la edición que presento a continuación ofrezco el texto de la versión que hizo Bécquer de la ópera de Pietro Metastasio titulada Demofoonte. Ofrez- 
co el texto de Bécquer en el lado izquierdo y las correspondencias con el de Metastasio $^{30}$, incluidas las acotaciones, en el derecho. Dado que trato de ofrecer una edición del texto becqueriano que pretende ser a la vez crítica y paleográfica, indico la foliación según el manuscrito, y doy también la numeración de los versos que hay en cada página. En notas al pie doy aclaraciones puntuales de tipo crítico o paleográfico:

- las retractationes, es decir, las palabras, grupos de palabras o versos que fueron rectificados por el autor. Generalmente aparecen tachados (lo que indico poniendo el texto entre corchetes [ ]), pero no siempre es así.

- las dobles versiones de determinados pasajes o versos.

- las formas aberrantes ortográficamente que he corregido en el texto (p. ej., muger por mujer).

- los errores de concordancia (p. ej., presuroros paso por presuroso paso).

- los lugares en que mi transcripción discrepa con las de los editores anteriores: Leonardo Romero Tobar (R.T.) y Ricardo Navas Ruiz (N.R.). En lo que cabe tener en cuenta que la edición de R.T. ofrece una transcripción detallada del manuscrito (por lo que puede haber discrepancias también en la lectura de las retractationes) y la de N.R. no presenta estos detalles.

- los lugares en que los editores anteriores separaron los parlamentos de los personajes de manera diferente a la que aquí ofrezco.

- los lugares en que los editores anteriores atribuyen un parlamento a un personaje distinto del que aquí indico (esto solo afecta a la edición de R.T., que propone los posibles interlocutores en su edición, en lo que no se arriesga N.R., que sí lo hace, en cambio, en lo que respecta a la ordenación de los fragmentos).

En el texto que ofrezco he corregido la acentuación, muy escasa en el manuscrito, y la he actualizado atendiendo a la norma actual. También he corregido la puntuación de acuerdo con los hábitos actuales.

Aunque he corregido las formas ortográfica o gramaticalmente aberrantes, he conservado un vulgarismo, que es el empleo de la segunda persona del singular del pretérito indefinido en -stes en lugar de en -ste (del tipo fuistes por fuiste $)^{31}$. La no conservación de este vulgarismo implica alteraciones métricas, de modo que varios endecasílabos pasarían a decasílabos.

Empleo los paréntesis angulares $<>$ para restituir texto que falta (palabras inacabadas, a las que falta alguna letra, etc. $)^{32}$, excepto en el caso de

\footnotetext{
${ }^{30}$ Para el texto del Demofoonte sigo la edición de Elena Sala di Felice (Metastasio, 1965).

${ }^{31}$ La edición de R.T. enmienda este uso, conservado, en cambio, en la de N.R.

${ }^{32}$ R.T. usa en esos casos los paréntesis normales ( ), pero yo los he evitado para no incurrir en confusión con los pasajes donde el propio Bécquer emplea los paréntesis para indicar que hay un aparte por parte de un determinado personaje.
} 
vocablos que aparecen abreviados de forma intencionada, donde resuelvo la abreviatura poniendo en cursiva la parte restituida (p. ej., la q' del manuscrito se presenta como que).

Presento en cursiva las palabras o grupos de palabras que son fruto de la conjetura (cuando la lectura no es clara). Estas conjeturas van entre signos de interrogación $i$ ? cuando mi seguridad frente a las mismas es escasa.

Cuando la lectura de alguna palabra me resulta del todo imposible marco la laguna con la abreviatura /il./ de «ilegible».

He mantenido el uso de las mayúsculas del autor, excepto cuando este uso viene condicionado por la puntuación (donde ha primado esta) o cuando se trata claramente de nombres propios (topónimos o antropónimos; en palabras relacionadas con la divinidad como numen, manes o dioses mantengo la forma del manuscrito por no observarse un criterio claro).

\section{Texto de la tragedia clásica de Bécquer: ${ }^{33}$ Demofoontes o La hija del poeta}

(escena II)

32r/DIR. ${ }^{34}$ Padre, padre, se fue. ¡Cuántos temores ${ }^{35}$ Se 'l mio principe almeno

(Dircea e poi Timante) vv. 51-90

${ }^{33}$ La numeración de las páginas que ofrezco es la que presenta el manuscrito en su estado actual (la misma que sigue R.T. en su edición). Algunas páginas presentan otra numeración que detallo a continuación (la primera forma es la de la numeración actual, y la forma entre paréntesis corresponde a otra numeración): 3v (6v; el 6 ha sido rectificado convirtiéndolo en un 9 y añadiéndole un 1, resultando así un 91); $4 \mathrm{v}$ (7v; el 7 ha sido rectificado convirtiéndolo en un 2); 7v (10v; el 1 ha sido rectificado convirtiéndolo en un 7 , resultando así un 70); 8v (12v); 9v (13v); 31v (38v); 32r (39r); 39v (50v); 43v (57v); 44r (60r; tachado); 45v; 46r; 46v; 147r (85r); 147v (85v). No obstante, las numeraciones alternativas no conducen a la inteligibilidad del drama. Alguna afecta a la ordenación del texto del Hamlet (esta numeración afecta, en nuestro drama, al folio 43, que también sería el 43 del Hamlet, si bien lo que encontramos es un 57 de una tercera numeración).

${ }^{34}$ El siguiente pasaje empieza en la parte de abajo (el último tercio) del folio, del lado derecho (vv. 1-10; 45-54 de R.T). Los vv. 11-21 (7-20 de R.T.) se encuentran en la parte inferior izquierda. Los vv. 22-32 (21-32 de R.T.) están en la parte superior derecha del folio. Continúa en la parte superior izquierda (vv. 33-38; vv. 1-6 de R.T.). Sigue en la parte central derecha (vv. 39-50; vv. 33-44 de R.T.). De ahí pasa a la página anterior (fol. 31v), en la columna derecha (vv. 1-19; 17-36 de R.T.). Y continúa en la columna izquierda de ese mismo folio 31v (vv. 20-36; 1-16 de R.T.). En la zona central derecha del folio 32r hay dos poemas breves: Despunta el sol alegre, de los montes / dora las cumbres. El pastor gallardo / ${ }^{A}$ ordena sus rebaños ${ }^{B}$ y en la aldea / todo es contento ( ${ }^{\mathrm{A}}$ en el margen izquierdo

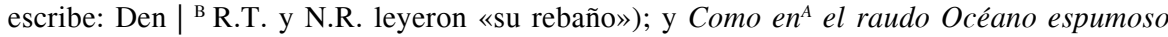
/ que ruge $e^{B}$, brama y lo revuelve airado / con esperanza el náufrago angustiado / mira próximo el faro luminoso, / lucha, se afana, llega presuroso ( ${ }^{\mathrm{A}}$ R.T. y N.R. transcriben «Como el raudo»| ${ }^{B}$ en ms.: ruje). N.R. incluye estos dos poemas entre los «Fragmentos inconexos» de la tragedia. Aunque en el ms. van seguidos, pueden considerarse dos poemas diferentes, no solo por el contenido, sino porque (como apunta R.T.) la tinta es diferente.

${ }^{35}$ [afectos] (R.T. idem). 
en este día ${ }^{36}$ el corazón me asaltan! De mi padre el amor quizá funesto para mí misma, la iracunda saña de rey potente que humillar queriendo ${ }^{37}$ a mi padre ${ }^{38}$, por la víctima señala a Dircea infelice. ¡Oh, si a lo menos lejos de aquí y ardiendo en la batalla en sangre, en polvo ${ }^{39}$ y sudor cubierto ${ }^{40}$ el príncipe esforzado no $10^{41}$ hallara! Si él ${ }^{42}$ de su triste y adorada esposa supiera el infortunio. Mas me engaña la esperanza tal vez o el que se acerca es Timantes. El mismo.

TIM. $^{43}$ ¡Esposa amada!

DIR. Silencio, por los dioses, ¿no recuerdas que aquí no resta ${ }^{44}$ en vida la vasalla unida al hijo de su rey ${ }^{45}$ ?

TIM. No temas, nadie puede escucharnos, y mi espada está y mi corazón, si <a> alguien oyes, prontos a defenderte.

DIR. No, ya calma mi pecho su temor. Pero ${ }^{46}$, cual numen amigo del amor de las batallas sangrientas y el estruendo, Belona te trajo al lado de tu esposa amada. TIM. De mi padre un mandato, y el deseo de volverte a mirar; pero la causa sabes de tal mandato.

DIR. ¡No, la ignoro!

TiM. Mas hablemos de ti. ¡Oh!, mi esperanza sola era de tus labios placenteros el acento escuchar. Dime ${ }^{47}$, adorada, cuando yo entre el clamor de las marciales ${ }^{48}$ quindi lungi non fosse... Oh ciel! Che miro? Ei viene a me!

5

Dolce consorte...

15 potrebbe udirti alcun. Rammenta, o caro, che qui non resta in vita suddita sposa a regio figlio unita. Non temer mia speranza. Alcun non ode; io ti difendo

20 ti rende a me?

$$
\text { E quale amico nume }
$$

25 Del genitore un cenno mi richiama dal campo né la cagion ne so.

Ma tu mia vita $m$ ' ami ancor? Ti ritrovo 30 qual ti lasciai? Pensasti a me?

${ }^{36}$ [mi triste corazón] (R.T. idem).

37 [mi padre] (R.T. idem).

${ }^{38}$ [quiero] y [queriendo] (R.T.: [queriendo]; por error, esta nota ha caído en el v. 43: «de mi padre»).

${ }^{39}$ Sobre «en sangre, en polvo», tachado: [no olvidé tu nombre] (R.T.: /ilegible/).

${ }^{40}$ R.T.: sudor cubierto | N.R.: (...)

${ }^{41}$ R.T.: la | N.R.: lo.

${ }^{42}$ R.T.: el | N.R.: él.

${ }^{43}$ R.T. atribuye este parlamento, donde incluye los dos siguientes, a Timantes.

${ }^{44}$ R.T.: ¿no verla? | N.R.: (...).

${ }^{45}$ [de sus reyes] (R.T. idem).

${ }^{46}$ R.T. y N.R.: penó cual.

${ }^{47}$ R.T.: ¿Dircea? | N.R.: dime.

${ }^{48}$ Encima de «las marciales»: [la agud<a $>$ ] y [lanzara]. 
trompas ayer en el campo batallaba, ${ }^{49}$

${ }^{50}$ tu agradable imagen entre el polvo

mirar creía cuando yo del alba

miraba la hermosura, y de tus ojos

la lumbre con la suya comparaba.

Dime: ¿pensaste en mí? ¿De algún suspiro

fue $^{51}$ hasta mi campo mensajera el aura?

DIR. ¿Y dudarlo podrás? ¡Oh, cuántas veces

a tiempo que del ${ }^{52}$ sol tras las montañas ${ }^{53}$

se ocultaba la frente y de $\mathrm{e}^{54}$ los bosques $^{55}$

40 chieder lo puoi? Puoi dubitarne?

\section{Ma come}

descendían las sombras enlutadas,

al cantar melancólico del ave

mis ardientes suspiros se juntaban!

¡Ay ${ }^{56}$, cuántas noches en sereno vuelo

el espacio cruzar la plateada

luna ${ }^{57}$ veía y de mis tristes penas ${ }^{58}$

en mi ilusión la causa le contara ${ }^{59}$,

que ella al par que estos campos silenciosos

también tu noble frente iluminaba!

$31 v /{ }^{60}$ Cuántas veces también, en la colina

donde te dije adiós, suspensa el alma

mirar creía aún el ardoroso

polvo que tu caballo levantara,

y de mis tristes ojos, conociendo

el engaño, una lágrima brotaba.

Si los Dioses, de mí compadecidos,

mis suspiros del céfiro en las alas

a ti hubieran llevado, no dirías

que si he pensado en ti. ¿Pensar? El eco ${ }^{61}$,

el eco lo dirá que en la callada

${ }^{49}$ Encima: [y con marciales trompas batallaba] | encima de la palabra más tachada que he conjeturado: clarines (R.T.: [y clarines /il./ trompas batallaba].

${ }^{50}$ Los siguientes versos (33-38) no se atribuyen a personaje alguno en la edición de R.T., quien los presenta como el inicio de este folio 32r (porque sigue el orden de aparición).

${ }^{51}$ R.T.: que | N.R.: fue.

${ }^{52}$ En ms.: de el.

${ }^{53}$ R.T.: la montaña | N.R.: las montañas.

${ }^{54}$ R.T.: (a)| N.R.: de.

55 [en los valles] (R.T.: [y en los valles]). Aparece una sola «y», que no está tachada.

${ }^{56}$ R.T. y N.R.: Oh.

${ }^{57} \mathrm{Cf}$. rima LXX: ¡Cuántas veces al pie de las musgosas / paredes que la guardan / oí la esquila que al mediar la noche / a los maitines llama! / ¡Cuántas veces trazó mi silueta / la luna plateada, junto a la del ciprés que de su huerto / se asoma por las tapias! (ya lo advirtió Pageard, 1990: 70).

58 [ayes] (R.T. idem).

${ }^{59}$ R.T.: contara | N.R.: contaba.

${ }^{60}$ Los versos que siguen se encuentran en la columna derecha del folio 31v (vv.1-19; vv. 17-36 de R.T.), cuyos versos tienen la continuación en la columna izquierda (vv. 2036; vv. 1-16 de R.T.).

${ }^{61}$ Debajo de «¿Pensar? El eco», tachado: [que si he pe<nsado>] (R.T.: [que si he pensado]). 
noche aun ${ }^{62}$ repite mi $<\mathrm{s}>$ sollozo $<\mathrm{s}>^{63}$ tristes

jugar $^{64}$ gimiendo entre $^{65}$ la selva sacra.

TIM. ${ }^{66}$ ¡Cuánta felicidad! No más ${ }^{67}$, Dircea, tu amor conozco y de él jamás dudara ${ }^{68}$; pero, perdona, de tus dulces labios escuchar repetirlo más me agrada. ¿Y el tierno Olinto, dime, y el querido ${ }^{69}$ hijo del corazón, la prenda cara de nuestro casto amor, dónde se halla? ¿Qué hace? Dime tú. ¿Crece en belleza? ¿Sobre su frente la hermosura radiante se dibuja? ¿El fruto se asemeja tal vez a mí? ${ }^{70}$ DIR. Al cielo, si enmudece; al rey, si habla ${ }^{71}$. Ya con trémulo labio tu querido nombre pronuncia y con incierta planta ya comienza a marchar; tiene prestada sobre su rostro ${ }^{72}$ esa fiereza ${ }^{73}$ noble $^{74}$ y bella que en el tuyo se retrata: ${ }^{75}$ cuando sonríe ${ }^{76}$ y en su blanca frente la alegría infantil veo grabada, me parece mirarte. ¡Oh, cuántas veces sobre el seno agitado lo estrechara ${ }^{77}$ creyéndote estrechar ${ }^{78} \tan$ dulcemente! El amor de los ojos me cegaba. $31 \mathrm{r} /{ }^{79}$

15 Non dubito ben mio; lo so che m' ami. Ma da quel dolce labbro troppo, soffrilo in pace, sentirlo replicar troppo mi piace. Ed il picciolo Olinto, il caro pegno

20 de' nostri casti amori che fa? Cresce in bellezza?

A qual di noi somiglia? 25 Egli incomincia

già col tenero piede orme incerte a segnar. Tutta ha nel volto

30 quella dolce fierezza che tanto in te mi piacque. Allor che ride, par l' immagine tua. Lui rimirando, te rimirar mi sembra. Oh quante volte credula troppo al dolce error del ciglio

35 mi strinsi al petto il genitor nel figlio.
Oh dio!

mi.

${ }^{62}$ R.T. y N.R.: aún (la métrica obliga a quitar esta tilde para conservar el endecasílabo).

${ }^{63} \mathrm{La}$ concordancia con «tristes» obliga a restituir la $-\mathrm{s}$ final de «mi sollozo» (así en ms.).

${ }^{64}$ [de selvas selva] (R.T.: [de /il./ selva]).

${ }^{65}$ R.T.: en | N.R.: dulce.

${ }^{66}$ Según R.T., el parlamento de Timantes empezaría en el verso anterior.

${ }^{67}$ R.T.: ¡Oh!, mas | N.R.: No más.

${ }^{68}$ R.T.: /il./ | N.R.: jamás dudara.

${ }^{69}$ Encima de «dime y el querido»: que arrebata (¿mi alma?; para completar el endecasílabo) (R.T.: Y el tierno Olinto, dime, y el /il./ | N.R.: ¿y el tierno Olinto, que arrebata, dime, y el querido).

${ }^{70}$ R.T.: ¿El fruto se asemeja tal vez a mí? | N.R.: (...).

${ }^{71}$ R.T.: en nota «al cielo /il./ al rey si habla» | N.R.: Al cielo, cielo, si enmudece; al rey, si habla (la métrica precisa eliminar el segundo «cielo»).

${ }^{72}$ [en su rostro] (R.T. idem).

${ }^{73}$ R.T.: fiereza | N.R.: firmeza.

${ }^{74}$ R.T.: notable | N.R.: noble.

${ }^{75}$ En el margen izquierdo, desde este verso hasta el v. 24 , escribe en vertical: $\mathrm{A}<\mathrm{h}>$ por qué marido $\mathrm{a}<\mathrm{h}>$ pobre. Hay otras anotaciones que no guardan relación con el drama: «Cuando del Betis», «Diomedes bajo la dirección», «Querido Monstruo»).

${ }^{76}$ Precede, tachado: [ríe].

${ }^{77}$ R.T. y N.R.: estrechaba (corrigiendo una posible lectura «estrechava»).

${ }^{78}$ [creyendo a ti estrecharte] (R.T. idem).

${ }^{79}$ Este pasaje, que en la obra de Metastasio se produce entre Timantes y Dircea, ha sido asociado por Bécquer al mito de Edipo, por lo que ha atribuido las palabras de Timantes 
$<$ DIR. $>^{80}$ [Yocasta, no, no llegues a ese lecho,

no lleg<u>es infeliz, que maldecido

por los Dioses está.]

Tim. ${ }^{81} \mathrm{Ah}$, ¿dónde, dónde está uno que era solo ${ }^{82} . .$. ? Ah dov'è? Sposa amata,

Llévame, por tu amor, donde se halla.

DIR. Modera tu cariño por ahora;

lejos de aquí, y en parte ${ }^{83}$ custodiado,

oculto vive ${ }^{84} \mathrm{y}$ el llegar a verlo

5 guidami a lui; fa' ch' io lo vegga.

muy seguro no $\mathrm{es}^{85}$. ¡Oh, cuántas ansias

cuesta nuestro secreto!

Affrena
signor per ora il violento affetto.
egli vive celato; e andarne a lui
non è sempre sicuro. Oh quanta pena

(que pregunta por su hijo Olinto) a Yocasta (cuyo hijo es Edipo). Y las palabras de Dircea (que le dice que su hijo Olinto está en un lugar oculto y lejano) han sido atribuidas a Layo, quien no quiere desvelarle dónde está su hijo Edipo (a quien ha mandado matar y que en realidad ha sido abandonado en un lugar lejano). R.T. incluye el siguiente fragmento entre los que llama «Fragmentos breves». Allí da también el frag. del fol. 39v que fue situado por N.R. entre los pasajes correspondientes al final del fol. $32 \mathrm{r}$ y el principio del $43 \mathrm{v}$ (en realidad va antes del fol. $4 \mathrm{v}$, como inicio del parlamento de Creúsa). También da R.T. dos frag. que N.R. ha relacionado con la versión de Hamlet que incluye el ms. (por eso los incluye entre los «Fragmentos sueltos» del Hamlet): fol. 76v/ ¿Por qué, Geruta, cuando más brillante ${ }^{A}$ / su divino fulgor de paz derrama / el Sol en nuestras frentes, y cercano ${ }^{D} /$ el momento que tanto desearas / miras, ese momento venturoso / que dando fin a mis ${ }^{E}$ amantes ansias / un porvenir de amores y grandeza, / abrirá a nuestros ojos ${ }^{F} /$ las barreras $^{G}$ que el cielo levantara / entre los dos $?^{H}$ (A Verso cruzado con dos rayas. ${ }^{\mathrm{B}}$ debajo de «de paz»: [al sol] (R.T.: [el sol]). ${ }^{\mathrm{C}}$ en ms.: derraman (plural inadecuado porque ha de concordar con «el Sol»). ${ }^{\mathrm{D}}$ [cuando miras] (R.T. idem). ${ }^{\mathrm{E}}$ encima: tus (R.T.: idem). ${ }^{\mathrm{F}}$ [la esperanza], [cuando rotas] y [y las vallas] (R.T. idem). ${ }^{\mathrm{G}}$ encima: [conociendo]. ${ }^{\mathrm{H}}$ al final del poema, escribe dos veces «Justo», y también leemos, como si fuera una firma, «Su Se» [¿Su Servidor?].). El otro poema es el siguiente (también incluido por N.R. entre los «Fragmentos sueltos» del Hamlet): fol. 96v/ Y con cautela y silenciosa planta / un vengador terrible de los muertos / penetra en la morada de sus padres, / pronto en la mano el homicida acero. ${ }^{I I} \mathrm{Al}$ lado y debajo de este poema escribe seis veces el nombre «Orestes»). En la edición de N.R., el fragmento de Yocasta (este nombre aparece escrito cuatro veces sobre el texto en el ms.) se incluye entre los que llama «Fragmentos inconexos», a los que añade dos poemas que aparecen en el fol. 32r (los he reproducido en la nota 34), lugar donde aparece parte del texto de la tragedia clásica. También incluye ahí lo que no es sino una versión alternativa del inicio del fragmento del fol. $43 \mathrm{v}$, donde de hecho se encuentra esta versión, separada por una raya horizontal.

${ }^{80}$ R.T., que deja como ilegible el final del v. (donde se lee «Edipo»), atribuye los parlamentos de este personaje a Edipo. No obstante, este primer parlamento de Dircea no tiene una correspondencia en el texto de Metastasio (por eso lo presento entre corchetes); sin duda fue escrito con posterioridad (se aprecia una tinta diferente y el margen que deja es diferente al del resto de este folio). Se trata de un parlamento atribuible a Layo a partir de la identificación de este encuentro entre Dircea y Timantes al correspondiente entre Layo y Yocasta en el mito de Edipo, de modo que las réplicas de Dircea se asocian a Layo y las de Timantes a Yocasta.

${ }^{81}$ Precede, tachado: [Ah, dónde está] (R.T. idem).

${ }^{82}$ Encima, con la misma tinta que los vv. 1-3: Edipo (R.T.: una /ilegible/ | N.R.: uno que Edipo).

${ }^{83}$ R.T.: y en parte | N.R.: en parte.

${ }^{84}$ Sigue, tachado: [tanta pena cuesta / nuestro secreto] (R.T. idem).

${ }^{85}$ Encima, ligeramente tachado: [no es muy seguro] (R.T. da esta variante, que aparece una sola vez en el ms., por duplicado: en nota y dentro del texto). 
TIM. $^{86} \quad$ Sí, y me causa ${ }^{87}$

ya el fingir el temor a cada instante, como si un crimen nos manchara el alma.

(escena III)

$44 \mathrm{r} /$

DEM. ${ }^{88}$ Cual príncipe y cual hijo dignamente cumpliste ya, dejando subyugadas vastas regiones a mi cetro. Ahora como rey, el perdón que me demandas a los cautivos doy. Y como padre, ¿qué te pudiera dar que compensara en algo tus fatigas ${ }^{89}$ ?

\section{TIM. (Oportuno} este momento es. Valor). De cuantas ${ }^{90}$ mercedes ${ }^{91}$ me pudiera el padre mío $\operatorname{con}^{92}$ ternura colmar, yo no estimara ninguna cual su amor; mas conociendo ${ }^{93}$ su bello ${ }^{94}$ corazón quisiera...

DEM. Nada

es lo que conoces comparado con lo que es para ti. Mucho más cara me es tu felicidad que tú imaginas, y lo que impreso tienes dentro el alma leo con dulce afán y aun adivino lo que tu pecho siente aunque lo calla. Receloso ${ }^{95}$ tu labio, tú quisieras gozoso al lado de tu esposa amada costa il nostro segreto!

10 Ormai son stanco di finger più, di tremar sempre. Io voglio cercar oggi una via d' uscir di tante angustie.

(Demofoonte e Timante) vv. 151-229 So che non piace

al tuo genio guerriero

la pacifica reggia; e il cenno mio che ti svelle dall' armi

5 forse t' incresce. I tuoi trionfi, o prence, e perché mie conquiste e perché tuoi, sempre cari mi son. Ma tu di loro mi sei più caro. I tuoi sudori ormai di riposo han bisogno. È del riposo figlio il valor. Sempre vibrato, alfine inabile a ferir l' arco si rende.

Il meritar son le tue parti; e sono il premiarti le mie. Se il prence, il figlio degnamente le sue compi finora, il padre, il re le sue compisca ancora. (Opportuno è il momento. Ardir). Conosco tanto il bel cuor del mio

10 tenero genitor che...

No, non puoi

conoscerlo abbastanza. Io penso o figlio

a te più che non credi;

15 io ti leggo nell' alma e quel che taci intendo ancor. Con la tua sposa al fianco vorresti ormai che ti vedesse il regno. Di’, non è ver?

\footnotetext{
${ }^{86}$ R.T. ve este parlamento como una continuación del anterior (atribuido por él a Edipo).

${ }^{87}$ R.T.: no causa | N.R.: me cuesta.

${ }^{88}$ Este parlamento no viene atribuido a personaje alguno en la edición de R.T., pero es obvio que corresponde al padre.

${ }^{89}$ [tus méritos en algo] (R.T. idem).

${ }^{90}$ [de cuantas / mercedes se dignara el padre mío] (R.T. idem).

91 [gracias].

92 Precede: [col<mar $>$ ].

93 [pero conozco] (R.T. idem).

${ }^{94}$ Encima, tachado: [tanto /ileg./] (R.T.: /ilegible/).

${ }^{95}$ [con recelo] (R.T. idem).
} 
que el reino ${ }^{96}$ te mirase. Di, Timantes ${ }^{97}$, ¿no es la verdad la que mis labios hablan? TIM. (Ya no hay duda. Ha descubierto el nudo que ante el cielo a Dircea me estrechara).

DEM. No osas hablar; aun más a complacerte 25 me estimulas. Timantes, el que guardas ${ }^{98}$ respetoso silencio lo declara. En la elección dudando vacilaba, que consentir en semejante nudo me pareció vileza y amée ${ }^{99}$ la llama ${ }^{100}$ del odio antiguo que a su padre tuve. $43 \mathrm{v} /{ }^{101}$ Dentro mi pecho ardía, mas ansiaba verte feliz, y a todo, este deseo sobrepujó. Timantes.

TIM. (No me engaña ${ }^{102}$ una ilusión falaz, no hay ${ }^{103}$ duda). Oh, padre, DEM: A paragon di questo nueva vida me dais. ¿Quién esperara tan grande ${ }^{104}$ recompensa? ¿Qué, decidme, vale el luchar fogoso en las batallas, qué las victorias, los sonoros ecos ${ }^{105}$ con que del mundo el ámbito la fama llena de nuestros nombres, comparados con tal felicidad? Vuelo en las alas llevado del amor, a mi querida esposa a conducir ante tus plantas. DEM. Ya tu hermano Querinto por mi orden la traerá hasta aquí.

TiM. ¿Qué inesperada ${ }^{106}$ 5 è lieve ogni riguardo. che mi stringe a Dircea).

(Certo ei scoperse il nodo

e a compiacerti appunto

il tuo mi persuade

rispettoso silenzio. Io lo confesso

dubbitai su la scelta. Anzi mi spiacque.

$30 L^{\prime}$ 'acconsentire al nodo abborria nella figlia. Alfin prevalse il desio di vederti felice o prence. TIM: nuova vita or mi dai. Volo alla sposa per condurla al tuo piè.

10

il tuo minor germano

la condurrà.

15 Che inaspettata è questa

${ }^{96}$ En ms.: reyno.

${ }^{97}$ Detrás, con una tinta que no refleja el facsímil: justos Dioses / ya no hay ¿estad $<0>$ ? (R.T.: [justos dioses]).

${ }^{98}$ R.T.: qué aguardas | N.R.: que guardas.

${ }^{99}$ R.T. y N.R.: amar.

${ }^{100}$ Encima de «y amé la llama», tachado: [y una guardada].

${ }^{101}$ Los versos que siguen empiezan tras una raya horizontal que ha trazado el autor. Sobre esta encontramos un inicio alternativo (R.T. lo reproduce en la nota 157 de su edición] | N.R. relega esta versión alternativa a la sección de «Fragmentos inconexos»): DEM. Dentro de mi pecho ardía mas ansiaba / verte feliz, y a todo, este deseo / sobrepujó. TIM. [En qué manera osara $]^{A}$ / dudar por un instante. Padre amado, / nueva vida me dais. Llevado en ella / del amor como ansioso a mi querida ${ }^{B} /$ esposa a conducir ante tus plantas $\left({ }^{\mathrm{A}}\right.$ debajo: [y por cuál empresa osara] [R.T.: /ilegible/ | N.R.: (...)]. ${ }^{\mathrm{B}}$ precede a «querida»: [esposa] | bajo «ansioso a su querida»: al lado de su esposa [R.T.: del amor como a su esposa ${ }^{1 \mathrm{~A}} /$ ill./ querida ( ${ }^{1 \mathrm{~A}}$ ¿lado de su esposa) | N.R.: del amor, cómo ansío a mi querida].).

${ }^{102}$ R.T.: engañas | N.R.: engaña.

${ }^{103}$ R.T.: hay | N.R.: ha.

104 [tamaña] (R.T. idem).

${ }^{105}$ Encima, tachado: [qué las fatigas, el peligro < ¿valen?>] (R.T.: [los trabajos, el peligro]).

${ }^{106}$ Bajo el prefijo in-, tachado: [no] (R.T. idem); ines- aparece superpuesto a «[no] esperada». 
felicidad esta!

DEM. ${ }^{107}$ Presuroso,

en compañía de mis nobles marcha

al puerto, y a su arribo se presente ${ }^{108}$

al puesto ${ }^{109}$. Y cuando ya la inspirada

nave llegue ${ }^{110}$ las olas divi<d $>$ iendo $^{111}$,

advierte...

TIM. Mas, ¿cuál nave?

DEM. La que $<a>$ Tracia $^{112}$

llega desde la Frigia conduciendo

la princesa real ${ }^{113}$ que destinaba

yo para esposa tuya ${ }^{114}$ como premio

de tu noble valor y tus hazañas?

46v/ TIM. (Justos dioses, ¿qué escucho?)

DEM.

extraño? Verdad es que la her<ed $>\mathrm{ada}^{115}$

indignación ${ }^{116} \mathrm{q} u e$ entre los frigios reyes

y los tracios ardiera no dejaba

esperar tal unión. Mas tranquila

paz $^{117}$ solo así podemos aguardarla.

$\mathrm{Y}$ un rey no trae consigo siendo sola

hija de un rey anciano.

TIM. No pensaba... ${ }^{118}$

Crei $^{119}$, padre ${ }^{120},\left(\mathrm{oh}^{121}\right.$, funesto desengaño)

¡Oís ${ }^{122}$ cuán presto se huyeron ${ }^{123}$ mis $^{124}$ doradas 10

ilusiones! ¿Qué anuncia tu silencio?

DEM. Otra esposa más digna y que vasalla no sea para ti.

TIM. ¿Dónde se encuentra? felicità!

$V$ 'è per mio cenno al porto

chi ne attende l' arrivo.

TIM. Al porto!

DEM. Equando

20 vegga apparir la sospirata nave

avvertiti sarem.

Qual nave?

che la real Creusa

Quella

conduce alle tue nozze.

25

(Oh dei!)

Ti sembra

strano, lo so. Gli ereditari sdegni

de' suoi, degli avi nostri un simil nodo

non facevan sperar. Ma in dote alfine

5 ella ti porta un regno. Unica prole

è del cadente re.

(Oh error funesto!)

Signor... Credei...

${ }^{107}$ R.T. y N.R. ven los versos que siguen, hasta el final de la hoja, como un único parlamento del padre.

${ }^{108}$ R.T.: presenta | N.R.: presente.

${ }^{109}$ R.T.: puerto | N.R.: puesto. En el ms. se lee «puesto», pero corresponde al lugar donde, en la obra de Metastasio, Timantes lo interrumpe para decir «¡Al porto!».

${ }^{110}$ En ms.: llege (R.T.: llega | N.R.: llegue).

${ }^{111}$ R.T. y N.R.: dividiendo.

112 R.T.: que Tracia | N.R.: que a Tracia.

113 [la hija de imis?].

114 En ms.: tulla.

115 Precede, tachado: [la hereditaria] (R.T.: la que her(eda)da ${ }^{\mathrm{A}}$ [la hereditaria] | N.R.: la que heredada).

${ }^{116}$ Encima, tachado: [indignación] (R.T. idem).

117 Sigue, tachado: [dejamos] (R.T. idem).

${ }_{118}$ R.T. atribuye este final de verso al final del parlamento del padre.

${ }^{119}$ En ms.: crey.

120 Sigue, tachado: [O funesto] (R.T. idem).

121 En ms.: O.

${ }^{122}$ R.T.: Oís | N.R.: Oh.

123 En ms.: hulleron.

124 [tan] (R.T. idem). 
Sea súbdita ${ }^{125}$, Señor, o Soberana, ¿qué importa?

DEM. Eso jamás. De nuestros nobles reyes los sacros manes se indignaran contra mí, que del trono la grandeza no supe conservar y la sagrada ley que nuestros mayores nos legaron que condena a morir a la que osada uniose al hijo de su rey. Sería sacrílego el que osase quebrantarla ${ }^{126}$.

TIM. Pero esta ley...

DEM. Silencio, ¿no escucháis ${ }^{127}$ jubilosos acentos? Mas Adrasto ${ }^{128}$ llega... (¡Oh, Dios!, ¿qué será?) ADR. ${ }^{129} \quad$ Ya dividiendo del ancho mar las ondas azuladas vese la nave que feliz conduce la princesa de Frigia. Y las montañas los jubilosos ecos ya repiten con que el pueblo gozoso $\mathrm{le}^{130}$ hace salva. DEM. Vuela, Timantes, a encontrar tu esposa.

TIM. Yo ${ }^{131}$.

DEM. En júbilos sin fin arda la Tracia.

A los dioses de amor ricas ofrendas ofrezcamos $^{132}$ y ardiendo las sagradas ${ }^{133}$ $45 \mathrm{v} /$ antorchas de Himeneo y vuestras almas ${ }^{134}$ jubiloso placer $^{135}$ solo respiran y la mía amargura. Yo a la playa contigo fuera, mas al sacro templo un funesto deber hora me llama. TIM. Marchad. Señor ${ }^{136}$, espera. (¡Oh, Dios! ¿Qué hace $<\mathrm{i}>\mathrm{sme}^{137}$ ? ) Ferma, senti signor.

che importa o padre.

15 Ah no; troppo degli avi ne arrossirebbon l' ombre. È lor la legge che condanna a morir sposa vassalla unita al real germe; e finch' io viva saronne il più severo

20 rigido esecutor.

$$
\text { Ma questa legge... }
$$

\section{Signor giungono in porto} le frigie navi.
30 vola o Timante.

$$
\text { Ad incontrar la sposa }
$$

Io?

Si. Con te verrei; ma un funesto dover mi chiama al tempio.

\footnotetext{
125 En ms.: suddita.

${ }^{126}$ En ms.: queblantarla.

${ }^{127}$ [no escuchastes] (R.T., enmendando el vulgarismo: [no escuchaste]).

128 Debajo de «mas Adrasto», tachado: [Ya a la playa] (R.T. y N.R., sin respetar el endecasílabo ni la tachadura del autor: jubilosos acentos? Mas Adrasto a la playa).

${ }^{129}$ R.T. y N.R. incluyen este parlamento dentro del correspondiente al padre.

${ }^{130}$ Leísmo (con referente femenino).

${ }^{131}$ R.T. y N.R.: Ya (presentan el parlamento que sigue, correspondiente al padre, como continuación del de Timantes: Ya en júbilos...). En el ms. está clara la «o» de «Yo», y «En» empieza con mayúscula.

${ }^{132}$ Sigue, tachado: [a la triste /il./ara] (R.T.: /ilegible/).

133 Sigue un verso que se ha de eliminar porque lo recompone al principio del fol. $45 \mathrm{v}$, donde sigue este pasaje. El verso dice así: antorchas de himeno [sus fulgores] ${ }^{\mathrm{A}}\left({ }^{\mathrm{A}}\right.$ debajo, también tachado: [y ¿el batir?]). R.T.: la sagrada / antorcha de humo ${ }^{\mathrm{A}}$ [ ${ }^{\mathrm{A}}$ sus fulgores /ilegible/] | N.R.: la sagrada / antorcha de (...).

${ }^{134}$ [en el alma] (R.T.: [y en el alma]).

135 [de todo el placer] (R.T. idem).

136 R.T. atribuye estas dos primeras palabras a Dircea (N.R. solo separa «Marchad»).

${ }^{137}$ R.T. y N.R.: ¿qué hacer?. En ms. leemos «hacesme», pero leer «hácesme» implicaría un final de verso esdrújulo, lo que resultaría insólito en el drama.
} 
Escuchadme, señor.

DEM. ¿Qué quieres? Habla ${ }^{138}$.

Parla. Che brami?

TIM. Confesarte..., decirte... (¡Oh, lo que angustio Confessarti... (Che fo?) Chiederti... (Oh dio que el sacrificio, que la ley ${ }^{139}$ infausta lo consiente! ¡ $\mathrm{Oh}^{140}$, tormento; oh, sacrificio che angustia è questa!) Il sagrificio, o padre, oh, ley horrible ${ }^{141}$, esposa desgraciada!)

10 la legge... la consorte... DEM. ¿Qué dudas ${ }^{142}$, qué recelas? Ya imposible es el volver atrás. Porque empeñada de un rey está la fe. Yo al ${ }^{143}$ rey de Frigia, en tanto que entra el vano [el] juramento ${ }^{144}$, le pedí la princesa. Yo, con galas y riquísimos dones, a Querinto envié a conducirla y necesario es conservar la fe de los que reinan ${ }^{145}$. Y tú, el grande en los campos de batalla, el héroe de Escitia, el valeroso ${ }^{146}$ príncipe, cuyo nombre de la fama en boca a las regiones más distantes es llevado, no creo que de hollarla serás capaz $\mathrm{a}^{147}$ un tiempo oscuresciendo ${ }^{148}$ la gloria de tu padre y de tu patria. (escena IV) (Oh legge! Oh sposa! Oh sacrificio! Oh sorte!)

Prence, ormai non ci resta più luogo a pentimento. È stretto il nodo; io l' ho promesso. Il conservar la fede

15 obbligo necessario è di chi regna; e la necessità gran cose insegna. Per lei fra l' armi dorme il guerriero; per lei fra l'onde canta il nocchiero; per lei la morte terror non ha.

20 Fin le più timide belve fugaci valor dimostrano, si fanno audaci, quand' è il combattere necessità. (Parte)

25

46r/ TM. ${ }^{149}$ ¿En qué, decidme, pudo a

númenes ofender la desgraciada, la infelice Dircea, en cuya afrenta el cielo todo su furor descarga? Vosotros, dioses, que la ardiente lumbre ${ }^{151}$ en sus ojos pusiste $<$ is $>$ que abrasara

Ma che vi fece o stelle

la povera Dircea che tante unite sventure contro lei! Voi che inspiraste i casti affetti alle nostr' alme, voi

5 che al pudico imeneo foste presenti, difendetelo, o numi; io mi confondo.

\footnotetext{
${ }^{138}$ Precede, tachado: [dime] (R.T. idem).

139 Sobre «que la ley», tachado: [lo consiente] (R.T.: /ilegible/).

${ }^{140}$ Precede, tachado: [O tor(mento)].

${ }^{141}$ En ms.: O, tormento; o, sacrificio; / o, ley horrible.

142 [qué te afli(ge)] (R.T.: [qué te afli].

${ }^{143}$ En ms.: a el.

144 Sobra el artículo «el» que precede a «juramento» (R.T.: en tanto que entra /il./ el juramento [por «entra el /il./ juramento»] | N.R.: en tanto que [...] el mismo juramento [este verso está añadido desde el margen izquierdo]).

145 En ms.: reynan.

${ }^{146}$ Hasta el inicio de este verso baja otro en diagonal: de cuantos amar saben decir / el amor (el cambio de renglón, que marco con una barra, se debe a que no cabe el endecasílabo completo).

147 R.T.: en | N.R.: a.

${ }^{148}$ [quebran<do>] (R.T.: un tiempo /il./ ${ }^{\mathrm{A}}$ [ ${ }^{\mathrm{A}}$ quebrar] | N.R.: un tiempo (...)).

${ }^{149}$ R.T. no atribuye este parlamento a personaje alguno.

${ }^{150}$ Preceden dos versos tachados que corresponden a un inicio alternativo: [En qué pudiera la infeliz Dircea, / númenes, ofenderos] (R.T. idem).

${ }^{151}$ Precede un verso tachado: [Vosotros, dioses, que un amor sagrado] (R.T. idem). R.T. y N.R. ponen los vv. 5-9 (más la primera mitad del 10, que en el ms. se repite), que en el ms. se encuentran en el ángulo inferior derecho, después del v. 18 (que en realidad es el último del fol. 46r).
} 
mi triste corazón, y que inspiraste $<\mathrm{i}>\mathrm{s}$ una dulce ternura en ${ }^{152}$ nuestras almas, ¿por qué a los golpes de fortuna ciega expuestos ${ }^{153}$ nos dejáis? ${ }^{154}$ ¿Por qué en amargas 10 horas de acerbo lloro las felices horas de nuestro amor se ven trocadas? ¿Qué hacer, qué resolver? En un inmenso ${ }^{155}$ tropel de confusiones triste vaga y perdida la mente. ¿Quién pudiera darme su ayuda y proteger mi causa? Tú lo harás ${ }^{156}$, Dios de amor, tú, en cuya mano la antorcha de $<\mathrm{H}>$ imeno sustentaba. $45 \mathrm{v}^{\text {cont. }} / 157$ Tú, que de nuestro amor la dulce prenda mentre salvar mi voglio sonriendo mirastes ${ }^{158}$, tú me ampara. Tú me apresta tu auxilio y de los Manes ${ }^{159}$ no temeré la furia temeraria. (escena $\mathrm{V}$ ) urto in un altro scoglio 30
M' oppresse il colpo a segno

che il cor mancommi e si smarrì l' ingegno. Sperai vicino il lido; ma trasportar mi sento fra le tempeste ancor. E da uno scoglio infido del primo assai peggior. (Parte)

(Porto di mare festivamente adornato per l'arrivo della principessa di Frigia. Vista di molte navi, dalla più magnifica delle quali al suono di vari stromenti barbari e preceduti da numeroso corteggio sbarcano a terra) (Creusa e Cherinto) vv. 246-332'

$39 \mathrm{v} /{ }^{160}$ CRE. Hoy que de nuevo el regalado aroma Ma che t' affanna, o prence? aspiras de las flores de tu patria, Perché mesto così? Pensi, sospiri, que después de surcar los anchos mares llegas feliz a las queridas playas que te vieron nacer, ¿dime, Querinto, por qué sobre tu frente...? ${ }^{161}$

$4 \mathrm{v} /{ }^{162}$ De una amiga tiernísima el consuelo taci, mi guardi; e se a parlar t' astringo con rimproveri amici

5 molto a dir ti prepari e nulla dici. Dove andò quel sereno allegro tuo sembiante? Ove i festivi

${ }^{152}$ R.T.: a | N.R.: en.

153 En ms.: espuestos.

${ }^{154}$ Esta primera mitad del verso va seguida de una continuación tachada: [porque si tantas / lágrimas costaran nuestras ¿acciones?] (R.T.: [porque si tantas lágrimas costaran nuestras]). Ahí termina la primera columna (que en el ms. es la derecha, y está bajo la segunda columna de un poema que no pertenece al drama), continuando el texto la columna izquierda (debajo de la primera columna del citado poema). Esta segunda columna (la izquierda del ms.) empieza recuperando, a modo de reclamo, el final de la columna anterior (espuestos nos dejáis), y continúa.

155 Precede a «en un inmenso», tachado: [vaga perdida].

156 En ms.: aras.

${ }^{157}$ Estos versos (del 27 al 30 del fol. 45v) están tras una raya horizontal al final de la hoja.

${ }^{158}$ R.T. (que corrige este vulgarismo como criterio de edición) y N.R. (que lo suele respetar): miraste.

${ }^{159}$ R.T.: /il./ | N.R.: manes.

${ }^{160}$ R.T. relega este fragmento a la sección de «Fragmentos breves» sin atribuirlo a personaje alguno. N.R., como en el resto del drama, tampoco lo atribuye a ningún personaje.

${ }^{161}$ R.T.: por quéA ${ }^{\mathrm{A}}$ sobre la ¿́frente?] | N.R.: por qué sola...

${ }^{162}$ R.T. considera estos dos primeros versos como parte del parlamento de Querinto. N.R. los separa. 
en algo tu secreto revelara ${ }^{163}$.

QUE. ${ }^{164}$ Si lo estimara ${ }^{165}$ yo, pudiera acaso ${ }^{166}$ ni del $^{167}$ Olimpo en las alturas sacras ${ }^{168}$ tesoro $^{169}$ hallar que de tus rojos labios ${ }^{170}$ una palabra sola compensara ${ }^{171}$. Quieres te descubra este secreto que yo juré encerrar dentro del ${ }^{172}$ alma para que en el silencio de las tumbas con mi triste infortunio se olvidara. Pue $<$ s $>{ }^{173}$, óyeme ${ }^{174}$, Creúsa ${ }^{175}$. Desde el día, desde el instante... ¡Dios, qué tormento me oprime el corazón, me angustia el alma! Ah, perdona, perdona; mi silencio tal vez será mejor. Tú te indignaras contra mí si del pecho comprimido el dolor que le agobia te mostrara ${ }^{176}$. CRE. Por el cielo, Querinto, que lo estoy ya de tu indiferencia. Mas ${ }^{177}$ tú callas porque, al fin, soy mujer ${ }^{178}$ y en las mujeres ${ }^{179} 20$ no es seguro un secreto. Me olvida $<\mathrm{b}>\mathrm{a}$ de eso, Querinto. Vamos al palacio. Tienes razón callando.

QuE. ¡Oh Dios, aguarda! Hablaré. No te indignes. En mi alma no hay momento ${ }^{180}$ de paz, tú me la robas. detti ingegnosi? In Tracia tu non sei qual eri in Frigia. Al talamo le spose in sì lugubre aspetto $s$ ' accompagnan fra voi? Per le mie nozze qual augurio è mai questo?

Se nulla di funesto presagisce il mio duol, tutto si sfoghi,

5 o bella principessa, tutto sopra di me. Poco i miei mali accresceran le stelle. Io de' viventi già sono il più infelice.

CRE. E questo arcano

10 non può svelarsi a me? Vaglion sì poco il mio soccorso, i miei consigli?

CHER. Evuoi ch' io parli? Ubbidirò. Dal primo istante... Quel giorno... Oh dio! No, non ho cor. Perdona,

15 meglio è tacer. Meritarei parlando forse lo sdegno tuo.

Lo merta assai già la tua diffidenza. È ver ch' alfine

20 io son donna e sarebbe mal sicuro il segreto. Andiamo, andiamo. Taci pur; n’ hai ragion.

Fermati. Oh numi!

Parlerò; non sdegnarti. Io non ho pace; 25 tu me la togli; il tuo bel volto adoro;

${ }^{163}$ R.T.: revelaras | N.R.: revelará.

${ }^{164}$ Este parlamento y el anterior están unidos en un solo parlamento de Querinto en R.T.

165 R.T.: ¿estimase? | N.R.: (...).

${ }^{166}$ Verso alternativo tachado: [darme consuelo que sepulta $\mathrm{a}^{\mathrm{A}} \mathrm{mi}$ alma] ( ${ }^{\mathrm{A}}$ : en) | R.T.: [/ il./ a mi alma] | N.R.: darme consuelo que (...) a mi alma (lo incluye dentro del texto pese a estar tachado y formar pareado con el siguiente, rompiendo así la rima alterna).

${ }^{167}$ En ms.: de el.

${ }^{168}$ R.T.: sacras | N.R.: (...).

169 [ventura] (R.T.: [/il./]).

170 [negros ojos] (R.T.: [tus negros ojos]).

171 Preceden dos versos tachados: [una lágrima sola compensara /dichoso fuera yo si mereciera] (R.T. idem).

172 en ms.: de el.

${ }^{173}$ R.T.: pue(s) | N.R.: pues.

${ }^{174}$ [escucha] (R.T. idem).

175 R.T. y N.R.: Creusa.

${ }^{176}$ [el turbulento afecto te mostrara] (R.T.: [el /il./ afecto te mostrara].

177 R.T.: mas | N.R.: más.

${ }^{178}$ En ms.: muger y en las mugeres.

179 [que su secreto].

${ }^{180}$ R.T.: momentos | N.R.: momento. 
De tu rostro las gracias soberanas adoro ciegamente, sé que en vano, y me siento morir. Esa es la causa de mi oculto dolor.

CRE. ¡Qué atrevimiento! Sabes $^{181}$ que soy la esposa destinada a tu hermano Timantes...

QUE. ¿No te dije que quizás mis razones te indignaran? CRE. Más amistad de ti, mayor respeto esperaba, Querinto.

QuE. Tal audacia culpa es de amor.

CRE. No más de aquí escuchar ${ }^{182}$ Cuida no hablar de amor una palabra. ${ }^{183}$

7v/ QUE. (Esto es una mujer ${ }^{184}$. De lo más hondo del triste pecho tu secreto arrancan, y luego lo desprecian). Mas, Creúsa ${ }^{185}$, ya que fuistes tú misma quien forzaras ${ }^{186}$ mi labio a que el delito balbuciera, escúchame un instante.

CRE. ¿Qué palabras pudieran disculparte? ¿Qué decirme podrás?

QUE. Que ${ }^{187}$ si de amor la ardiente llama $^{188}$ por ti alimenta el pecho, si te adoro, soy digno de piedad. Y si es culpada ${ }^{189}$ mi pasión, no soy yo, Demofoontes es el reo. No hubiera en toda Tracia otro mejor que él que hasta ${ }^{190}$ la Frigia ${ }^{191}$ súbdito fiel portara a su ${ }^{192}$ embajada, otro más ${ }^{193}$ insensible o más helado que hasta el pie te trajera de las aras. Si del espeso bosque hasta los cielos 30

5 so che l' adoro invano;

e mi sento morir. Questo è l'arcano.

Come! Che ardir..
Nol dissi
che sdegnar ti farei!
più rispetto da te. $\begin{array}{r}\text { Sperai Cherinto } \\ \text { Colpa d'amore... }\end{array}$

35 Taci, taci. Non più. (Volendo partire)

tu volesti o Creusa

Ma già che a forza

il delitto ascoltar, senti la scusa.

Che dir potrai?

Che di pietà son degno, s' ardo per te. Che se l' amarti è colpa,

10 Demofoonte è il reo. Doveva il padre per condurti a Timante altri sceglier che me. Se l' esca avvampa, stupir non dee chi l' avvicina al fuoco. Tu bella sei, cieco io non son. Ti vidi,

15 t' ammirai, mi piacesti. A te vicino ogni dì mi trovai. Commodo e scusa il nome di congiunto

\footnotetext{
${ }^{181}$ R.T.: saber | N.R.: sabes.

${ }^{182}$ R.T.: escuchar | N.R.: (...).

${ }^{183}$ Cf. vv. 309'-310 de Metastasio: Ma più d'amore / guarda di non parlarmi.

${ }^{184}$ En ms.: muger.

${ }^{185}$ [si te fingen] (R.T.: si tu figura) (y luego lo desprecian si tu figura) y [detente] (R.T. idem) (y luego lo desprecian. Detente) | R.T. y N.R.: Creusa.

186 R.T.: forzara | N.R.: forzaras.

187 R.T.: Qué | N.R.: Que.

188 Al margen: Clamor / Clamor de que.

189 A continuación (en el margen), tachado y con otra tinta, como verso alternativo al que sigue: [es causa de amor el dardo crudo].

${ }^{190}$ R.T.: ¿de? | N.R.: hasta.

191 [fuera] (R.T.: [Tracia], a pesar de formar terceto con los versos que lo encierran en vez de la rima alterna que se emplea en todo el poema).

${ }^{192}$ R.T.: portara la embajada | N.R.: portara su embajada.

${ }^{193}$ [que] (R.T. idem).
} 
la silbadora llama se levanta, no debe sorprenderse el que encendida la sacra ${ }^{194}$ antorcha en él dejó olvidada. Tú, más que el cielo al despuntar la aurora tiñéndolo ${ }^{195}$ en cambiantes de oro y grana, eres Creúsa ${ }^{196}$ bella $^{197}$.

${ }^{198}$ Bella eres tú, ciego no soy, y apenas tu hermosura miré, dentro del alma fogosa que me alienta, inexplicable sentí una sensación. Yo suspiraba. Honda y lenta tristeza a mis mejillas quitaba[n] su frescura, y yo ignoraba el porqué. Junto a ti, cuando el divino Apolo, en la mitad del cielo lanza sus ardorosos rayos, cuando nace y cuando en occidente se desmaya, no podía vivir si de tus ojos

la ardiente y pura lumbre no mira $<$ ba $>{ }^{199}$.

CRE. (Cuántas, cuántas veces a mí misma me pregunté, Querinto, el qué te afana ${ }^{200}$. $147 \mathrm{r}{ }^{201} ¡ \mathrm{Oh}$ !, dioses, ¿por qué quise de esos arcanos ${ }^{202}$ que el profundo misterio revelara?

Me siento enternecer, pero el decoro lo primero será.)

QUE. Creúsa ${ }^{203}$, callas.

CRE. Tan loco atrevimiento me sorprende y de estupor me llena. mi diè per vagheggiarti; e me quel nome non che gli altri ingannò. L' amor che sempre

20 sospirar mi facea d' esserti accanto mi pareva dovere. E mille volte a te spiegar credei gli affetti del german, spiegando i miei.

\footnotetext{
194 Encima: antorc(ha) (R.T.: /il./).

195 R.T. y N.R.: tiñiéndolo.

196 R.T. y N.R.: Creusa.

197 Siguen tres versos tachados: [tú más que tu alma venia ese bello / yo no soy ciego,
} te miré y el alma / fogo(sa) que me alienta ciegamente] (R.T.: [Yo no soy ciego, te miré y el alma / que me alienta ciegamente]).

${ }^{198}$ En el fol. 20r encontramos una segunda versión de estos versos: Tú eres más bella que la pura lumbre / que el cielo tiñe al despuntar rosada / la aurora. Por mi mal no nací ciego. / Tú eres más bella que la pura lumbre (R.T. idem). N.R. introduce estos cuatro versos entre los versos 23 y 24.

199 R.T.: mira(ba) | N.R.: miraba.

${ }^{200}$ R.T.: ¿afana?| N.R.: (...). Cf. v. 246 de Metastasio: Ma che t'affanna, o prence?

${ }^{201} \mathrm{Al}$ principio de esta página leemos las siguientes anotaciones relacionadas con la estructura del drama: «Aquiles / acto $1^{\circ}$ Tumba de Héctor: Príamo, Eneas, Edipo, Paris, siervos, nobles y pueblo. Se hace / la esposición [sic] / y de estupor me llena / Aquiles / acto $1^{\circ} /$ Acto $1^{\circ} »$. La frase «y de estupor me llena» corresponde al v. 6 de esta página. (R.T., introducción, p. 31, transcribe: «Acto $1^{\circ}$ - Tumba de Héctor, Príamo, Paris, nobles»). Debajo de estas anotaciones, antes de empezar el texto propiamente del drama, escribe este poema lírico: No bala triste el simple corderillo / que (en) el umbroso bosque se perdiera / y que cercano escucha de la fiera / tigre el mugir, / con tan hondo dolor como yo gimo /del Betis manso en la frondosa orilla ${ }^{A}$ ( ${ }^{\mathrm{A}}$ [a las oriyas del Betis anchas]).

${ }^{202}$ R.T.: ese arcano | N.R.: esos arcanos.

${ }^{203}$ R.T. y N.R.: Creusa. 
QuE.

¡Qué insensatas ${ }^{204}$

las ilusiones son que el hombre forja! ${ }^{205}$ ¡Cuán presto desvanece la esperanza ${ }^{206}$ la triste realidad! Me parecía, (no lo querrás creer), que nuestras almas sin hablar entre sí se comprendían. Los fuga $<\mathrm{c}>$ es suspiros que escapaban del hondo de tu pecho, una suave y dulce languidez que en tu mirada me pa<r>eció observar, creer me hicieron que era amor tu amistad.

CRE.

Querinto, basta. 147v/ QUE. ${ }^{207}$ Entiendo me aborreces y deseas que lejos de ti parta.

Bárbara, partiré solo y errante. Del $^{208}$ insondable piélago a las bravas ondas me entregaré, pidiendo al cielo que mi nave en el seno de las aguas sumerja $^{209}$ con furor, que de las altas ${ }^{210}$ nubes un rayo ardiente desprendido sobre la frente de Querinto caiga. Y si el cielo a mi ruego despiada $<$ do $>$ de mi dolor no escucha las plegarias, si a mi pesar la vida me conserva lejos de aquí y en extranjera playa,
Epure

talor mi lusingai che l' alme nostre $s$ ' intendesser fra loro senza parlar. Certi sospiri intesi;

10 un non so che di languido osservai spesso negli occhi tuoi, che mi parea molto più che amicizia.

\begin{tabular}{|c|c|}
\hline & Or su Cherinto \\
\hline & della mia toleranza \\
\hline & cominci ad abusar. Mai più d' amore \\
\hline & guarda di non parlarmi. \\
\hline CHER. & Io non comprendo... \\
\hline CRE. & Mi spiegherò. Se in avvenir più saggio \\
\hline & non sei di quel che fosti infin ad ora, \\
\hline & non comparirmi innanzi. Intendi ancora? \\
\hline & $T^{\prime}$ intendo, ingrata, \\
\hline & vuoi ch' io m' uccida. \\
\hline & Sarai contenta; \\
\hline & m’ ucciderò. \\
\hline 5 & Ma ti rammenta \\
\hline & ch' a un' alma fida \\
\hline & l'averti amata \\
\hline & troppo costò. (Vuol partire) \\
\hline CRE. & Dove? Ferma. \\
\hline 10 & $\begin{array}{l}\text { CHER. No no. Troppo t' offende } \\
\text { la mia presenza. (In atto di partire) }\end{array}$ \\
\hline CRE. & Odi Cherinto. \\
\hline CHER. & E troppo \\
\hline
\end{tabular}

${ }^{204}$ Siguen dos versos tachados, versión alternativa de la continuación: [ilusiones forjé. Me parecía, / creerlo no querrás, que nuestras almas] (R.T. idem); en ms.: forgé.

${ }^{205}$ Sigue un verso alternativo tachado: [mira si loco fui. Me parecía / cuan] (R.T. idem).

${ }^{206}$ Sigue un verso alternativo, del que solo tacha la primera parte: [el leve soplo] pensaba a veces (R.T. [el leve soplo, pensaba a veces]).

${ }^{207}$ Precede este verso una palabra ilegible (R.T., que hace constar la palabra /il./ en el texto - a diferencia de N.R.-, pone aquí una nota, la 187 de su edición, donde dice: «Gustavo (añadido interlineado)», por clara confusión, ya que este nombre, con rúbrica, aparece entre los versos 12 y 13 ).

${ }^{208}$ En ms.: de el.

${ }^{209}$ R.T.: (se) sumerja (formando un dodecasílabo y cambiando el sentido) | N.R.: sumerja.

${ }^{210}$ En el margen izquierdo escribe, por encima de este verso, cinco versos (el tercero está tachado) que son una versión alternativa a los versos 6-11: un vasto rayo [ardiente] de las nubes / sobre la frente de Querinto caiga / [librándole de vida tan amarga] / y si el cielo a mi ruego despiadado / de mi dolor no escucha la plegaria $\left(^{\mathrm{A}}\right.$ esta palabra está tachada. Encima escribe: y desprendido [dado que «vasto» está sobre «un rayo», acaso podemos reconstruir: y un rayo desprendido de las nubes]. R.T. lo incluye dentro del verso al reproducir esta variante en su nota 188). 
solo con mis pesares, pronto el numen ${ }^{211}$

ruin de la muerte, a las calladas

márgenes del Leteo, con medroso

lúgubre acento llamará mi alma.

Pero no esperes, no, que aunque venturas ${ }^{212}$ gozarás, plácida calma, no que ${ }^{213} \mathrm{mi}$ aunada ${ }^{214}$ sombra por doquiera seguirá amenazante tus pisadas. El viento que en la noche ${ }^{215}$ silenciosa gime triste en la selva ${ }^{216}$ solitaria creerás son los lúgubres lamentos con que lloro mi suerte desgraciada. En el pálido rayo de la luna que ilumina las ondas plateadas verás cruzar errante y vagoroso mi espíritu. En las aras sacrosantas cuando a jurar amor ${ }^{217} l$ leg $<\mathrm{u}>\mathrm{e}<\mathrm{s}>$, gigante 30 entre el humo verás que se levanta mi sombra entre los dos. Y nunca, nunca del $^{218}$ amor gozarás, que a las airadas furias del hondo ${ }^{219}$ Averno mi terrible ${ }^{220}$ venganza les dejo encomendada. (escena $V I$ )

148r/ CRE. Dime, ¿qué /ileg./ es esta?221 TIM. ${ }^{222}$ Vuestras virtudes, vuestra noble cuna ${ }^{223}$ en rostro ${ }^{224}$ de gracias sobrehumanas no ya de mí, de un ${ }^{225}$ numen será digno. ${ }^{226}$ Que no puede romperse, y yo la causa ni la he dicho a mi padre, ni pudiera. A vos toca evitar en vuestra fama abuserei restando

15 della tua toleranza. (Come sopra)

CRE. t' impose di partir?

E chi finora

Comprendo assai

anche quel che non dici.

20 CRE Ah prence, ah quanto mal mi conosci. Io da quel punto... (Oh numi!)

CHE: Termina i detti tuoi.

CRE. Da quel punto... (Ah che fo?) Parti, se vuoi.

CHER. Barbara partirò; ma forse... Oh stelle!

25 Ecco il german.
35

(Timante frettoloso e detti) vv. 342-358

Che avvenne?

\section{I nostri}

genitori fra noi strinsero un nodo che forse a te dispiace,

5 ch' io non richiesi. I pregi tuoi reali sarian degni d' un nume non che di me; ma il mio destin non vuole

\footnotetext{
${ }^{211}$ [genio] (R.T. idem).

${ }^{212}$ R.T.: venturas | N.R.: ventura.

${ }^{213}$ R.T.: No, que | N.R.: que. El «no» está escrito con una tinta que no se refleja en el

${ }^{214}$ R.T. y N.R.: aterrada. Precede, tachado: [odiosa] (R.T. idem).

${ }^{215}$ Encima de «noche», no tachado: que entra (R.T.: [que /il./]).

${ }^{216}$ Encima de «selva», no tachado: juncosa (R.T.: [selva]).

${ }^{217}$ Bajo «amor», tachado: [lleg<u>es] (R.T. idem).

${ }^{218}$ En ms.: de el.

${ }^{219}$ Precede, no tachado: a.

${ }^{220}$ Debajo, tachado: [hasta la feroz] (R.T.: ¿terrible ${ }^{\mathrm{A}}\left[{ }^{\mathrm{A}}\right.$ no /il./ la feroz] | N.R.: (...)).

${ }^{221}$ R.T.: Dime, Querinto /il./ | N.R.: Querinto, (...). El uso de la forma italiana «Cherinto» en todo el poema impide leer aquí «Querinto», pues lo que se lee más claro es el inicio «que». De la palabra «Dime» no hay rastro en el facsímil porque la tinta es ahí muy clara.

${ }^{222}$ R.T. atribuye este parlamento a Querinto.

${ }^{223}$ R.T.: ¿savia? | N.R.: (...). En el facsímil (que reproduce el microfilm del manuscri-
} facsímil. to) no hay rastro de esta palabra que sí se lee en el original.

${ }^{224}$ R.T.: en rostro | N.R.: (...).

${ }^{225}$ R.T.: mi | N.R.: un.

${ }^{226}$ Sigue una línea horizontal que trazó el autor. 
recibir una ofensa. $\mathrm{Al}^{227}$ soberano decidle que este enlace os desagrada. Y en vez mía, vos misma refutadme, agravad mis deméritos, mis faltas. ${ }^{228}$ Yo os perdono ${ }^{229}$ y quizás os bendijera si con vuestro desprecio se salvara mi secreto y mi vida. ch' io possa esserti sposo. Un vi si oppone invincibil riparo. Il padre mio

10 nol sa; né posso dirlo. A te conviene prevenire un rifiuto. In vece mia $v a$, rifiutami tu. Di' ch' io ti spiaccio; aggrava, io tel perdono,

i demeriti miei; sprezzami e salva per questa via, che il mio dover t' addita, l' onor tuo, la mia pace e la mia vita. Come!

CRE. ${ }^{230}$ Mas oídme.

Teco io non posso

TIM. ${ }^{231} \mathrm{Me}^{232}$ es imposible. ${ }^{233}$ Tú, cuida llevarla 15 con la pompa debida a una princesa hija de reyes frigios.

CRE. Pero escuchadme ${ }^{234}$, príncipe.

TiM. No puedo. trattenermi di più. Prence alla reggia sia tua cura il condurla. (Partendo)

Ya os he dicho, señora, cuanto el alma mía os pudo ${ }^{235}$ decir. A vos os toca Dissi tutto il cor mio; Ah dimmi almeno... mis razones seguir o desecharlas. (escena IX) 20 né più dirti saprei. Pensaci. Addio. (Parte) 3v/ DIR. Ah, por piedad, señor, ¿dó me lleváis,

(Matusio esce furioso con Dircea per mano) vv. 400-415 dónde me conducís? ?36 A mis palabras, ¿por qué calláis, medroso, a todas partes la cabeza tornando? ¿Dó me arrastra vuestro furor, adónde?

MAT. $\quad \mathrm{Al}$ más desierto paraje de la Libia, a las calladas y sombrías florestas do rugiendo se escucha con pavor la tigre hircana. De la salvaje Escitia a las cavernas, a la tierra ${ }^{237} \mathrm{de}^{238}$ Tracia más lejana, donde mire entre ti y estas riberas las roncas olas de las mares bravas. DIR. ¡Ay de mí! MAT. $^{239} \quad$ ¿De qué sirven los afanes,

5 sen della Libia, alle foreste ircane, fra le scitiche rupi, o in qualche ignota, se alcuna il mar ne serra, separata dal mondo ultima terra.

10

\section{(Aimè!)}

\section{Sudate o padri}

${ }^{227}$ Precede, tachado: [id] (R.T.: ilegible).

${ }^{228}$ R.T. atribuye los tres versos que siguen a Creúsa (N.R. también ve aquí un cambio de interlocutor).

${ }^{229}$ Encima, tachado: [yo te perdono] (R.T. idem).

${ }^{230}$ R.T. atribuye este parlamento a Querinto.

${ }^{231}$ R.T. atribuye este parlamento a Creúsa.

${ }^{232}$ Encima, tachado: [no] (R.T. idem); podemos reconstruir: no <puedo>.

${ }^{233}$ R.T. atribuye las palabras que siguen al padre.

${ }^{234}$ R.T. atribuye «Pero escuchadme» a Querinto, «Príncipe, no puedo» a Creúsa, y el resto también a Querinto (N.R. comparte esa misma separación de parlamentos).

${ }^{235}$ R.T.: pudo | N.R.: puede.

${ }^{236}$ [fuera de vos] (R.T. idem).

${ }^{237}$ [a la más] (R.T.: [a la /il./]) ¿a la más lejana tierra de Tracia?

238 [más] ¿a la tierra más lejana de Tracia?

${ }^{239}$ R.T. atribuye a Dircea este parlamento (N.R. tampoco ve aquí un cambio de interlocutor). 
de qué sirve el amor con que a la cara prenda de vuestro pecho, en el inmenso piélago de maldad donde fracasa doquier la virtud, prestáis ayuda? ¿Qué derechos, oh padres ${ }^{240}$, da tan santa, tan justa obligación?
DIR.
(Ah, soy perdida.

El lazo descubrió ${ }^{241}$ que yo ocultaba ${ }^{242}$ ). ¡Padre, piedad!

MAT. Piedad ${ }^{243}$ ya no la hay ni justicia, ni fe. $\mathrm{No}^{244}$, atropellada se encuentra la razón y la inocencia. Ya todo se ha perdido.

DIR. A vuestras plantas vedme, señor.

MAT. ¿Qué haces, infelice?

DIR. Quiero regar con lágrimas amargas el suelo. Quiero, triste, suplicaros con sollozos un porqué.

MAT. Levanta ${ }^{245}$. Otra cosa que llanto en este instante nos $^{246}$ pide el cielo.

DIR.

$\mathrm{Sabe}^{248}$..., no puedo.

MAT. $^{249}$ Espérame que un leño ${ }^{250}$ quiero buscar ${ }^{251}$ que a ultramares te traiga $^{252}$. (escena $X$ )

$8 \mathrm{v} /$ DIR. Nos aleja, oh, del cielo ${ }^{253}$ el más piadoso numen, mira la pena que desgarra mi triste corazón. Como las olas del $^{254}$ hondo mar en las desnudas playas unas tras otras vienen a estrellarse, así a romper mi pecho las desgracias en día tan aciago y tan funesto nella cura de' figli. Ecco il rispetto

15 che il dritto di natura,

che prometter si può la vostra cura.

(Ah scoprì l' imeneo! Son morta). Oh dio 20 signor pietà.

Tutto è perduto.

Non v'è pietà né fede.

Ecco al tuo piè...

25

Io voglio pianger tanto...

Che fai?

Il tuo caso domanda altro che pianto.

30 Sappi...

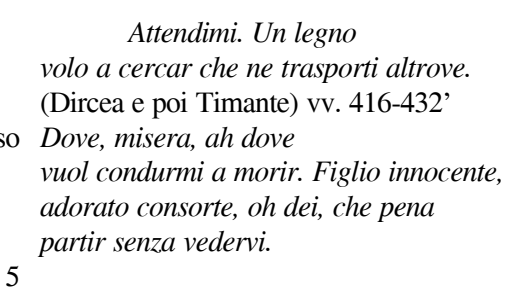

\footnotetext{
${ }^{240}$ R.T. y N.R.: padre.

${ }^{241}$ [Descubrió el himeneo] (R.T.: [Descubrió el Himeneo]).

242 En ms.: ocultava.

${ }^{243}$ R.T. pone esta palabra como la última del parlamento de Dircea. N.R. la separa.

${ }^{244}$ R.T.: Oh | N.R.: No.

${ }^{245}$ R.T.: Levantar | N.R.: Levanta.

${ }^{246}$ R.T.: no | N.R.: nos.

${ }^{247}$ R.T.: Mas | N.R.: Más.

${ }^{248}$ R.T. y N.R.: sola.

${ }^{249}$ R.T. y N.R. ven este parlamento incluido en el anterior.

${ }^{250}$ R.T.: ¿leño?| N.R.: (...).

${ }^{251}$ R.T.: /il./ (todo el verso) y, como otro verso, «quiero ${ }^{\mathrm{A}}$ vueles a buscar» [ ${ }^{\mathrm{A}}$ buscar] |

N.R.: quiero (...) buscar.

${ }^{252}$ Debajo: vueles a buscar.

${ }^{253}$ R.T.: (...) nos aleje del cielo | N.R.: Nos aleja. Oh del cielo (en ms.: O del cielo).

${ }^{254}$ En ms.: de el | [sobr<e>] (R.T.: [sobre]).
} 
unas tras otras llegan. Desgraciada de mí. ¡Ah! ¿Dónde quiere el padre mío conducirme a morir, hijo del alma, esposo, ¡ah!, sin poder adiós deciros?

Voy a expirar ${ }^{255}$.

TIM. Al fin, esposa amada, te encuentro.

DIR. Adiós ${ }^{256}$. Timantes ${ }^{257}$, en funesta hora has llegado. Adiós ${ }^{258}$. En pena tanta algún consuelo tengo: que a lo menos escuches tú mis últimas palabras. Adiós por siempre. Solo ${ }^{259}$ a tu paterno amor queda la prenda encomendada que más amé en la tierra. Tú en mi nombre abrázalo. Tú dile, cuando el alma suya capaz de la piedad ya sea, cuál fue mi triste suerte, y una lágrima vierta por mi memoria.

TiM. ¿Qué me dices, qué nuevo mal sucede? Tus palabras me hacen temblar.

DIR. Mi padre ha descubierto nuestro arcano ${ }^{260}$, y ardiendo en ira y saña hallome ${ }^{261}$ en el palacio. Silencioso, en su frente severa se pintaba la indignación que apenas comprimía. Con presuroso ${ }^{262}$ paso aquí me arrastra. En vano me arrodillo, en vano riego con $^{263}$ llanto amargo el suelo que pisaba. $9 \mathrm{v} /$ Inflexible a mis ruegos una nave voló a traer, que presto me arrancara de tus brazos. $\mathrm{Yo}^{264}$, Esposo, no lo ignoro, ya acabó para mí toda esperanza.

TIM. No tiembles ${ }^{265}$, no. Timantes a tu lado se encuentra.
10

Alfin ti trovo

Ah caro sposo addio

e addio per sempre. Al tuo paterno amore

15 raccomando il mio figlio.

Abbraccialo per me. Bacialo e tutta

narragli, quando sia

capace di pietà, la sorte mia.

20

Sposa che dici? Ah nelle vene il sangue gielar mi fai!

25

Certo scoperse il padre

il nostro arcano. Ebro è di sdegno e vuole quindi lungi condurmi. Io lo conosco, per me non v' è più speme.

30

5 lo smarrito tuo cor, sposa diletta, al mio fianco tu sei.

${ }^{255}$ En ms.: espirar. Debajo: [morir] (R.T. idem) | a continuación, tachado: [¿dó hay pena más amarga?] (R.T. idem).

${ }^{256}$ R.T.: Oh, Dios | N.R.: Adiós.

${ }^{257}$ Encima, tachado: [Oh Dios, Timan<tes>] (R.T.: Oh Dios, dime).

${ }^{258}$ R.T.: ;Oh, Dios! | N.R.: Adiós.

${ }^{259}$ Precede, tachado: [a] ( $i$ a solo tu paterno?).

${ }^{260}$ Encima, tachado: [el nudo] (R.T. idem) / [el juramento sacro que enlazara / tu suerte con la mía] (R.T. idem | N.R. incorpora «el juramento sacro que enlazara / tu suerte con la mía» entre los versos 25 y 26).

${ }^{261}$ En ms.: hayome.

${ }^{262}$ En ms.: presurosos (inadecuado, porque si restituimos la $-\mathrm{s}$ de «paso» resulta un dodecasílabo).

${ }^{263}$ [con].

${ }^{264}$ Precede, tachado: [adiós] (R.T.: [Oh, Dios]).

${ }^{265}$ [No temas] (R.T. idem). 
(escena XI)

MAT. $^{266}$ Ven, Dircea, desgraciada ${ }^{267}$.

(Matusio torna frettoloso e detti) vv. 432'-445

DIR. Ya no ${ }^{268}$ hay remedio. ¡Adiós!

TIM.

Jamás, Dircea, Dircea non partirà.

de aquí no partirás.

MAT. ${ }^{269} \quad$ ¿Quién con audacia Chi l' impedisce?

lo pudiera estorbar?

TIM. Yo. Io.

Mat. Come!

DIR. ${ }^{270}$ Dios piadoso.

Dircea t' affretta.

MAT. Yo con el hi<e $>r<r>0^{271}$ la paterna causa 10 defenderé.

TIM. $\quad$ No temo tus furores ${ }^{272}$, que tengo corazón y no mi espada cuelga inútil al lado.

DIR. ¡Padre mío, príncipe!

MAT. ${ }^{273}$ Por piedad. ¿Crueldad tanta quién vio jamás? ¡Que un hijo de Belona, un héroe victorioso en las batallas el hierro vil desnude ${ }^{274}$ contra un ${ }^{275}$ padre porque a su hija de la muerte salva, porque a una pura virgen inocente quiere alejar de las crueles playas do le espera la muerte!

DIR. $^{276} \quad$ (iOh ${ }^{277}$, Dios!)

TIM. ¿qué dice...?

DIR. Yo..., señor... Ah, detente ${ }^{278}$. (Yo engañada estoy, nada sabía).

\author{
Aimè! \\ Difenderò col ferro \\ la paterna ragion. (Snuda la spada) \\ Col ferro anch' io \\ la mia difenderò. (Fa lo stesso) \\ Prence che fai! \\ Fermati, o genitore. (Si frapone) \\ Empio! Impedirmi \\ 15 che al crudel sacrificio una innocente \\ vergine io tolga?
}

0

\section{(Oh dei!)}

Ma dunque...

(Ah taci.

(Piano a Timante fingendo trattenerlo)

Nulla sa; m' ingannai).

\footnotetext{
${ }^{266}$ R.T. y N.R. presentan este parlamento incluido en el anterior.

267 «desgraciada» aparece tachado (restituido aquí por necesidad métrica: para completar el endecasílabo). R.T. lo mantiene en nota por estar tachado.

${ }^{268}$ Encima, tachado: [suerte] y [de mí] (R.T.: [de mí]).

${ }^{269}$ R.T. atribuye este parlamento a Dircea. N.R. no da el nombre del personaje, como en toda su edición, pero introduce un cambio de escena después del verso 13 atendiendo, seguramente, a la presencia del padre.

${ }^{270}$ R.T. y N.R. ven este parlamento y el siguiente como parte del anterior (es decir, en boca de Timantes).

${ }^{271}$ La palabra «hierro» está escrita debajo en tinta más clara (no se aprecia en el facsímil).

${ }^{272}$ Siguen estos versos tachados: [con el hierro también. Yo de estas playas / no dejaré que partas. También tengo] (R.T.: [con el hierro también. Yo de estas playas / no dejaré que parta. / También tengo]). N.R. incorpora los versos «con el hierro también. Yo de estas playas / no dejaré que partas» entre los versos 11 y 12.

${ }^{273}$ R.T. y N.R. ven este parlamento como parte del anterior.

${ }^{274}$ R.T. y N.R.: desvíe.

${ }^{275}$ R.T.: un | N.R.: su.

${ }^{276}$ Parlamento atribuido a Timantes por R.T.

${ }^{277}$ En ms.: O.

${ }^{278}$ R.T. atribuye «ah detente» a Timantes.
} 
MAT. $^{279} \quad$ ¡Que en su sangre

Volerla oppressa!

quiera, impío, ver bañada el ara!

DIR. (Solo un momento y el temor me vende 25 (Io quasi per timor tradii me stessa).

y me acuso yo misma).

TIM. Si mi espada

desnudé contra vos, perdón merezco.

Lleno de indignación ${ }^{280}$ te vi.

Signor perdona. Ecco l' error. Ti vidi verso lei che piangea correr sdegnato; tempo a pensar non ebbi; opra pietosa il salvarla credei dal tuo furore.

\section{BIBLIOGRAFÍA CITADA}

Alonso, Dámaso (1961). «Un diario adolescente de Bécquer», ABC, 19-8-1961 (reproducido en su libro Del Siglo de Oro a este siglo de siglas. Madrid: Gredos, 1962, pp. 107122).

ANÓNIMO (1920). «Páginas inéditas de Bécquer», América Latina: Revista de propaganda europea en las repúblicas latino-americanas. Año 6. $\mathrm{N}^{\mathrm{o}} 8$ (agosto), p. 10 (el director era Benjamín Barrios, posible autor).

ARMiÑÁN, Luis de (1939). «Papeles viejos. El cuaderno casero del padre de Gustavo Adolfo», Domingo (12-11-1939).

BÉCQUER, Gustavo Adolfo (1993). Autógrafos juveniles (ed. Leonardo Romero Tobar). Barcelona: Puvill.

BÉCQUER, Gustavo Adolfo (1995). Obras completas (ed. Ricardo Navas Ruiz). Madrid: Turner (2 vol.).

BÉCQUER, Gustavo Adolfo (2004). Obras completas (ed. Joan Estruch Tobella). Madrid: Cátedra.

CAMPILLO, Narciso (1871). «Gustavo Bécquer», La Ilustración de Madrid. 25 (15-1-1871), pp. 2-3.

GAMAllo De Fierros, Dionisio (1948). Del olvido en el ángulo oscuro: páginas abandonadas de Gustavo Adolfo Bécquer. Madrid: Valera.

Metastasio, Pietro (1965). Opere, (ed. Elena Sala di Felice). Milano: Rizzoli Editore.

MORENO Godino, Francisco (1886). «G. A. Bécquer: Semblanza», La Ilustración Artística. 684, pp. 115-116.

Moreno MengíBAR, Andrés (1997). «La formación operística de Gustavo Adolfo Bécquer: los años sevillanos (1848-1854)», El Gnomo. 6, pp. 59-89.

PAGEARD, Robert (1990). Bécquer: leyenda y realidad. Madrid: Espasa.

SEBold, Russell P. (1999), «Bécquer en sus comienzos neoclásicos», Salina. 13, pp. 71-80.

Segovia, Alberto de (1927). Gustavo Adolfo Bécquer, Madrid: Figuras de la Raza: Revista semanal hispanoamericana. 15 (17-2-1927)

Manuscritos de Bécquer Consultados

Autógrafos (Ms. 22.511 de la Biblioteca Nacional de Madrid).

«Pensamientos de obras originales» y «Proyectos de obras y publicaciones» (Ms. 171 de la Fundación Vicente Huidobro, Santiago de Chile).

Fecha de recepción: 22 de julio de 2010

Fecha de aceptación: 2 de marzo de 2011

${ }^{279}$ R.T. considera estos versos como parte del parlamento de Dircea.

${ }^{280}$ Encima, tachado: [yo vi a Dircea] (R.T.: [yo vi, sí, Dircea]). 